O2016, Elsevier. Licensed under the Creative Commons Attribution-NonCommercialNoDerivatives 4.0 International http://creativecommons.org/about/downloads

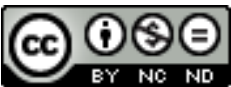




\title{
EMBEDDING REAL OPTIONS IN SCENARIO PLANNING: A NEW
}

\section{METHODOLOGICAL APPROACH}

\author{
By Giampiero Favato and Riccardo Vecchiato \\ Kingston Business School
}

\begin{abstract}
The main goal of this paper is to explore whether and how we might integrate real options analysis into scenario planning in order to overcome the limitations and enhance the benefits of both techniques. So far scholars have emphasized that the main advantages of scenarios consist in developing the learning and adaptive skills of organizations. We thus investigate how to develop further these learning skills. Our paper contributes to the strategic management literature in three ways. First, it illustrates a new and simplified methodological approach to real option valuation. Second, it embeds this methodological approach into the $2 \times 2$ scenario matrix technique. Third, it deepens our understanding of the advantages that the combined use of scenarios and real options might bring to each technique.
\end{abstract}

\section{Keywords}

Scenario planning; real options; organizational learning; pay-off method; $2 \times 2$ scenario matrix. 


\section{Introduction}

The joint effects of globalization, rapid technological changes, and deregulation contributed to the relentless rise of new customer needs and business models and thereby to the growing volatility of the business environment. In a chaotic world in which markets and entire industries continuously emerge, collide, split, evolve, and decline, strategic investment decisions require managers to be able to sense, seize and handle external changes quickly (Teece, 2007).

Various foresight practices and techniques ('strategic - or corporate - foresight') have been developed to support strategic planning in fast-paced environments and thus help decision makers cope with uncertainty (Battistella and De Toni, 2011; Rohbreck and Schwarz, 2013; Vecchiato and Roveda, 2010). Scenario planning, in particular, has been used for more than 40 years and has clearly emerged as one of the most popular and effective technique (van der Heijden et al., 2002). Scholars and practitioners developed a large number of different approaches to scenario planning. However, all these approaches share a common goal that is not to predict the future but rather to enhance organizational learning (Wright et al., 2013). The primary contribution of scenario thereby is to enable a process for strategic thinking that changes the established mental models of senior managers (Grant, 2003; de Geus, 1997).

Akin to scenarios, real option analysis has become considerably popular among both practitioners and scholars (Krychowski and Quelin, 2010). A real option is the right, but not the obligation, to make an investment in real assets by or at the end of a given period (Dixit and Pindyck, 1994). This method has been borrowed by the financial theory and then developed by strategic management scholars as a way to value investment in fast-paced environments.

Practitioners emphasize that scenarios, on the one hand, and real options, on the other hand, have specific strengths and weaknesses which are likely to complement each other (Cornelius et 
al., 2005). However, the extant literature offers little indication of how to combine scenario planning with real options so that we can cope with the differences between the qualitative analytical approach of scenarios and the quantitative analytical approach of real options (Miller and Waller, 2003).

This gap in literature represents a great opportunity for scholars and practitioners. The main aim of this paper is to explore how scenario planning and real options might be integrated in order to overcome their limitations and enhance their benefits, particularly in relation to the learning skills of organizations.

Our research efforts and practical experience enabled us to design and apply an innovative methodological approach which takes advantage of a recent technique for real options valuation and embeds this technique into the $2 \times 2$ scenario matrix. We developed this innovative approach in the specific context of R\&D investment decisions of a biotech company. However, the methodology we present might be seamlessly used in similar areas of corporate choices like mergers and acquisitions, investments in new capacity, international expansion. It might be easily extended as well to other business sectors.

One of the authors was directly involved in the application of the method as he served as advisor to the board of the company at the time of a critical investment decision for the clinical development of a new drug. Thanks to this privileged viewpoint, we got access to primary data and provided a detailed description of the application of the method and its outcomes. The authors were given explicit consent to the publication of the real inputs that informed the decision model, provided that fictional names were given to the company and its candidate for clinical development. 
Our paper contributes to the strategic management literature in three ways. First, it builds on the recent work of financial scholars to refine a new methodological approach to real option valuation. Second, it blends this methodological approach in the $2 \times 2$ scenario matrix. Third, it deepens our understanding of both scenarios and real options and the benefits and challenges inherent in the combined use of these two techniques. More generally, this research expands our understanding of how firms can cope with increasing volatility and uncertainty (Vecchiato, 2012).

\section{Uncertainty and strategic decision making: the role of scenario planning and real options}

Environmental uncertainty is the inability of decision makers to understand what are the major events or changes in their business environment (Knight, 1921; Duncan, 1972). Uncertainty represents a key challenge for strategic planning and investment decisions, as it affects the foundation of strategic planning itself: the possibility to make accurate forecasts (Ansoff, 1991; Porter, 1980). While relatively reliable in the short term, forecasting accuracy diminishes in the medium and long term as political, economic, social and technological drivers of change interact in novel and unforeseeable ways (Galbraith and Merril, 1996; Eisenhardt et al., 2010).

The challenge of crafting strategy in a fast-paced business environment has encouraged the design and development of new practices and techniques aimed at identifying external changes and anticipating their possible evolution (Graham and Harvey, 2001; Porter et al., 2004). Among these techniques, scenario planning and real options in particular have become very popular (O’Brien and Meadows, 2013; Avadykyan and Llerena, 2010). 


\subsection{Scenarios}

Scenarios represented a strong discontinuity from traditional forecasting approaches, the limits of which - i.e. the inability to make accurate enough predictions in the more and more volatile business environment - have been widely emphasized by strategic scholars (Doz and Kosonen, 2008; Mintzberg, 1990).

Instead of predicting the future, the main rationale of scenario planning is to envisage alternative views of the future in the form of different (but internally consistent) configurations of key changes in the business environment (Schoemaker, 1993). The most common school or methodology of scenario planning in corporate organizations is usually labeled as the 'Intuitive Logics' (Wright et al., 2013). This methodology requires to focus on arising uncertainties (i.e., new events or drivers of change) in the business environment and then to select, among all these arising uncertainties, the most critical ones to be used as the basic premises of a small number of scenarios. Here practitioners distinguish between two main approaches: the inductive method and the deductive method (Schwartz, 1991). The first one is loosely structured and relies on the ability to reach a broad consensus among a group of experts and decision makers. The deductive approach uses instead simple techniques of prioritization to build a $2 \times 2$ scenario matrix based on the two most critical sources of uncertainty (i.e., drivers of change) in the business environment. Both the inductive and the deductive approach are subjective and qualitative in nature.

The origins of the intuitive school of scenario planning date back to the 1950s, as the effort of the US Department of Defense to select the most critical projects (development of new weapons systems) led to the development of an approach known 'as system analysis'. Later on system analysis turned out to be the basis of the intuitive scenario methodology (Bradfield et al.: 
p. 33). The first scenario exercise described in literature on strategy is the "Year 2000" study that Royal Dutch Shell (hereafter Shell) carried out in 1967: this scenario exercise enabled the company to anticipate the discontinuities the oil industry was going to the face in the early 1970s, namely the impeding scarcity of oil and the increase in its price (Wack, 1985). Shortly afterwards, scenarios were widely adopted throughout Shell. In the 1970s, scenarios originally focused on the key variables relevant to the oil business, namely oil demand and price. Later on their focus gradually broadened to include the macro economic and political landscapes. In the 1980s a deeper analysis of social and environmental (ecological) changes was added, so that by 1987 Shell's scenarios filled three separate volumes on oil, energy and global trends in the macro environment. Afterwards, in the early 2000s Shell's scenarios started being framed around three different levels, from 'global' to 'focused' and 'project' scenarios. Shell global scenarios investigated major forces in the macro environment of the energy industry, i.e., the political, economic, ecological, social, and technological (PEEST) landscapes. Based upon global scenarios, Shell 'focused' scenarios' specifically addressed each business sector of the energy industry and each major country or region where the company was carrying out out its operations. Finally, 'project' scenarios considered major strategic investment decisions by drawing the implications of global and focused scenarios and by processing more detailed data on direct rivals, profitability, and technical and managerial issues. The main objective of these changes in Shell's scenario planning approach was to devolve strategic transparency and accountability from the corporate level to the over 50 strategic planning units of the company (Davis, 2002). Scenarios offered these units a tool and process for scrutinising the resilience of their strategic decisions: in the early 2000s, the Shell group committee of managing directors 
requested every strategic planning unit to prove the robustness of their strategy against the global scenarios and the supporting focused and project scenarios.

While Shell is largely recognized as the foremost user of scenarios among corporate organizations, a survey of US top firms revealed that in the early ' 80 s almost half of the US Fortune 1000 industrial companies were also using this planning approach (Linneman and Klein, 1983). For instance, GE began to experiment with scenarios at about the same time of Shell and in 1971 produced four alternative scenarios of global and US economic and socio-political conditions. Scenarios were very popular also among European firms (Malaska et al., 1985). More recently, BASF in the chemical sector, Daimler in the automotive industry, and Morgan Stanley in the financial sector provided further compelling examples of companies that have been largely applying scenarios (Vecchiato and Roveda, 2010; Vecchiato, 2012). Similarly to Shell, scenarios in these companies were built via a top-down process that started at corporate level, by firstly taking into account the global economy, and then elaborated more focused scenarios regarding specific business areas and investment projects.

\subsection{Real options}

Akin to scenarios, real options have become a very popular forward-looking technique among business executives. Real options are based on a quantitative approach rooted in the finance research: after their first introduction in the early 1990s, the literature quickly expanded and now offers a large number of increasingly complex models for the analysis and valuation of real options (Smit and Trigeogis, 2006, provide a comprehensive review of the literature on this subject). 
Before the development of real options theory, executives have based their understanding of the long-term profit of strategic investments on the discounted cash flow (DCF) approach. For instance, the net present value (NPV) of an investment project is calculated by focusing on the present value of expected streams of cash inflows and the present value of expected streams of cash outflows (Dixit and Pindyck, 1994). However, the traditional NPV approach has clearly a relevant limit: it ignores the benefits due to the ability to delay (or stop) irreversible investment decisions and thereby to profit from new information about key changes in the external environment, as long as this information becomes available.

Real options represented a significant discontinuity from the traditional DCF approach, as they involved the application of financial options theory to investment decisions on real assets (McGrath et al., 2004; Tong and Reuer, 2007). A financial option is the right, but not the obligation, to buy (call) or sell (put) a stock (the "underlying asset") at a fixed price (the "exercise price") by or at the end of a fixed period ("maturity"). Whereas financial options confer rights to buy or sell financial assets, real options have physical and knowledge-based resources as their underlying assets. Real option theory argues that a valuable risk reduction can result from breaking large investments into series of smaller decisions. The approach emphasizes that many initial investments (for example market tests, joint ventures, or operating licenses) create relevant opportunities that give the firm the chance (but not the obligation) to make subsequent follow-on investments (Dixit and Pindyck, 1994; Trigeorgis, 1996; Krychowski and Quelin, 2010). More precisely, real options confer possibilities either to acquire assets (call options) or divest assets (put options) in the future. If the economic prospects of the project turn out to be favourable, a firm may later decide to exercise the option - e.g., to launch the new product, to purchase the remaining capital of the joint venture, to build a plant for the new 
technology, or to operate the acquired license. Conversely, if economic circumstances are unfavourable, it will abandon the option — that is, it won't make any subsequent investment. The flexibility inherent in the opportunity (but not the obligation) to make further investments in additional assets, allows managers to take advantage of upside (gain) outcomes and avoid downside (loss) outcomes.

Given the roots of real options in the financial theory, the most popular methods for real option analysis are derived from the case of financial options (Krychowski and Quelin, 2010). That's the case in particular of the popular Black-Scholes model which requires five basic inputs. These are: the present value of the future cash flows stemming from the investment project (PV), the development cost of the real assets (X), the time the project may be deferred $(\mathrm{T})$, the risk-free rate of return (rf) and the volatility related to the PV $(\sigma 2)$. Out of these five inputs necessary to solve the Black-Scholes differential equation, volatility proved to be very relevant to option's value and yet the most difficult to estimate. ${ }^{1}$

Empirical studies on the implementation of real options covered a wide range of application domains. In capital intensive industries such as the oil business, real options were widely used in order to make decisions on major upstream investment projects (Chorn and Shokor, 2006; Paddock, Siegel and Smith, 1988; Smith and McCardle, 1999), More recently, real options were used in the case of the renewable energy sector (Boomsma, Meade, and Fleten, 2012). Other fields of application have been consumer electronics, where real options were used for

\footnotetext{
${ }^{1}$ Differently from financial option pricing, which uses continuous compounding of the standard deviation of historical returns to estimate the forward volatility underlying the stock price, real options must use surrogate measures of uncertainty, since historical returns on the same project are obviously not available. So far parameters such as historical returns of similar projects realised by the same firm or probabilistic analyses of historical data (e.g. Monte Carlo or Bayesian simulations) have been used to estimate the forward volatility of the project value's underlying the option. Nevertheless, the determination of volatility factor in the Real option pricing model is still an open issue.
} 
determining the optimal investment timing of the market introduction of a new product (Pennings and Lint, 2000); the bank sector, where real options were used for identifying the right time of introduction of a new IT system (Benaroch and Kauffman, 1999); and the real estate market (Rocha, Salles, and Garcia, 2007). Similarly, real options have been applied to assess investments under high uncertainty, like investments in new software platforms (Taudes, Feurstein, and Mild, 2000; Ullrich, 2013), or investments in environmental mining equipments (Cortazar, Schwartz, and Salinas, 1998).

Our literature review uncovered that, in particular, R\&D and high technology investment decisions represent a typical kind of strategic project that fits well with the real options logic. On the one hand, such investment decisions are taken in a context of a high level of uncertainty; on the other hand, these decisions can be managed in a flexible way because the investment process is sequenced in different phases. The pharmaceutical and biotechnology industries provide compelling examples. Kellogg and Charnes (2000) used real options in order to value a biotechnology company as the sum of its drug-development projects. Bowman and Moskowitz (2001) illustrated a case where Merck applied the real option approach to justify an investment in a new R\&D project. McGrath and Nerkar (2004) explored the application of patents in the pharmaceutical industry and showed that leading companies' investments in R\&D were well

aligned with the real option approach. Finally, Mills, Weinstein, and Favato (2006) illustrated the use of real options for valuing and timing the development of new drugs at Eli Lilly and Schering Plough.

\subsection{Combining scenarios and real options: benefits and challenges}


Thanks to the contributions of several scholars and practitioners, extant literature on uncertainty management provides a detailed analysis of the main advantages and disadvantages related to the use of either scenario planning or real option analysis. The comparison of these advantages and disadvantages is very helpful to shed light on how the integration of scenarios and real options might enhance their benefits - and overcome their limitations.

According to mainstream literature, the main advantages of scenarios are:

- Qualitative approach and system thinking: scenario planning builds on the insights and knowledge of different players within and outside a corporate organization. Scenarios provide an integrated framework that allows decision makers to clarify their assumptions about the drivers of changes that can affect the future evolution of the business environment. In particular, the intuitive school of scenarios spurs decision makers to reflect on the mutual influences of drivers of change and to envision alternative evolutions, by producing a series of stories about plausible and consistent future states of these drivers. In this way, scenarios support organizational learning and responsiveness to the shifting business environment: they "change the decision makers' assumptions about how the world works and compel them to reorganize their mental model of reality" (Wack, 1985: 74). More specifically, the qualitative insights, opinions, and beliefs of decision makers are turned into alternative visions of the future that go beyond the scope of the prior history of the company: these visions provide managers with a "head start, as well as a conceptual framework within which to scan, encode, update, and understand the future as it unfolds" (Schoemaker, 1993: pg. 200).

- Flexibility and adaptation: as they change the mental models of decision makers, scenarios establish a learning process that makes strategic investment decisions more 
flexible and adaptive (Davis and Pyper, 2015; de Geus, 1997; Grant, 2003; van der Heijden et al., 2012). The most relevant description of the learning process that scenarios inform is based on the concept of 'memory of the future', introduced by Professor David Ingvar. According to Ingvar (1987, p.128), human brains constantly probe the conditions of the outside world and then immediately look at the actions they can take, in a constant sequence, on alternative paths that run into different futures. Ingvar (1987, p.128) thus claimed that ideas "about the future, like memories of past events, can be remembered, often in great details": human brains not only build but also store these alternative time paths, which become 'memories of the future'. Memories of the future represent the basis for anticipations and expectations as well as for the short and long-term planning of goaloriented behaviours. People use their memories of the future for extracting meaningful information from the enormous and random sensory noise to which they are continuously exposed: such extraction would not be possible without memories of the future. A. de Geus, former head of scenario planning at Shell, comments:

"The hypothesis of Ingvar is that the function of the memory of the future is to allow the brain to select those signals that are relevant for you. [...] If you have only one possible alternative path into the future, you see-or hear-very little. This is the real importance of scenario planning. It stretches the time horizon from one or two years, to ten or twenty years. And paradoxically, while increasing the time horizon, at the same time, in the present, it increases the power of perception. You hear more signals that are relevant to you". ${ }^{2}$

- Externally focused: scenario planning pushes managers to continuously explore longrange opportunities and threats emerging in the external environment, by broadening their strategic focus beyond the boundaries of their organization (Bradfield et al., 2005,

\footnotetext{
${ }^{2}$ A. Geus, keynote speech 'The Living Company_Long Term Thinking in a Changing Society,' presented at the In the Long Run Conference, Berlin, Germany, October 18, 2004. See In the Long Run, (2005), Burmsteir, K. and Neef, A. (Eds.). Oekom: Munich, Germany.
} 
Schwartz, 1991; van der Heijden et al., 2012 ). Shell, BASF, and Daimler provide compelling examples in this regard (Vecchiato, 2010; 2012). Macro forces and their likely evolution are typically described in global scenarios that lay the foundations for the further investigation of specific business units and strategic investment projects.

- Coordination and communication: according to Kees van der Heijden (1996), former head of scenario planning at Shell, scenarios improve communication by creating and fostering the adoption of a common language for dealing with strategic issues. This common language definitely facilitates a strategic conversation within the organisation. As they improve communication, scenarios enhance coordination as well: during the scenario process, decision makers align their understanding of future opportunities, risks and objectives, so that they can coordinate their efforts and activities more easily (Amer, Daim, and Jetter, 2013).

On the other hand, the main limitations of scenarios are:

- Lack of consistency: internal consistency is definitely the key feature that allows scenarios to change the mental models of decision makers and thus enhance organizational flexibility and adaptation (Cornelius et al., 2005; de Geus, 1997; Schoemaker, 1993). Consistency relates to the capability to depict pictures of the future that capture the mutual influences of drivers of change: within each scenario, the future state of each driver should reflect the impact of the other drivers, and vice versa. Clearly, this capability strongly relies on the knowledge, expertise, and skills of the managers that are involved in the scenario building process: if managers are not able to figure out key drivers of change and their mutual influences, scenarios can trap managers themselves 
into wrong beliefs about the future business environment. In turn, these wrong beliefs can hamper, rather than enhance, the adaptive skills of an organization. Specifically, research on managerial cognition showed that, when the mental models/beliefs of decision makers are not aligned with the future evolution of the external environment, these mental models often result in organizational inertia and poor performance (Barr, Stimpert, and Huff, 1992). For instance, in the transition to digital imaging, Polaroid's commercialization strategy was driven and limited by beliefs inherent to the analog photography business model (Tripsas and Gavetti, 2000). The lack of internal consistency is likely to produce the same effects on decision makers, by contributing to the development of mental models that are not aligned with the changing external environment.

- Lack of quantitative data: the qualitative focus of intuitive scenarios often leads managers to overlook the task of quantifying the future value of drivers of change (Miller and Willer, 2003). Such lack of quantitative data might have many negative consequences. First, scenarios can result less vivid: managers can find it more difficult to grasp the essential features of scenarios. Second, managers might be prevented from fully understanding the impact of drivers of change on the organization, i.e., the financial outcomes of the scenarios. Third, the members of the organization that were not involved in the scenario process can have greater difficulty in grasping the scenarios themselves. Fourth, and most importantly, quantitative data might help to check - and thus enhance the internal consistency of scenarios.

- Bias of participants: dominant personalities might limit the range of the alternative scenarios that managers take into consideration and explore (Miller and Willer, 2003). 
Franco et al. (2013) explore the impact on scenarios of participants in the scenario workshops. Focusing on the different psychologies of individuals, they analyse modes of information gathering and information evaluation. These authors argue that the “cognitive styles" and personal (rather than organizational) objectives of participants determine the efficiency of the overall team in engaging with particular components of a scenario development process, such as selecting key drivers of change and plotting the scenarios.

In the case of real options, the main strengths of this technique are:

- Quantitative approach: real options provide a rigorous framework for reflecting on the future value of key drivers of change - and thus on their impact on the future profits of the organization (Krychowski and Quelin, 2010).

- Emphasis on flexibility: compared with the discounted cash flows approach, real options consider the potential value of a given investment choice - rather than the net present value. More specifically, real options explicitly consider the value created by the opportunity to postpone or stop irreversible investments in real assets (Dixit and Pindyck, 1994).

The main limitations are instead:

- Difficulty to value options in real assets: many of the inputs to option valuation have no direct-proxies outside a financial context. As they are basically derived from the financial literature, established models for real option analysis require the estimation of parameters that in the case of real assets are usually vague and questionable. That's for instance the 
case of volatility, which is one of the most relevant parameter used for financial option valuation and thereby for real option analysis. For instance, the holders of call options on the shares of a given company can base their analysis of volatility on the historical price of the company's stock (the option's underlying asset). In some cases, the volatility of the historical assets underlying real options are similarly observable. For instance, an oil company can estimate the volatility of its proven reserves by looking at the historical evolution of the price of oil. But in most cases, the value of the volatility of real assets is not so clear or cannot be observed at all (Copeland and Tufano, 2004). Let's consider the examples of an unmade movie or an untested drug: volatility cannot be gained simply through official statistics from Stock Exchanges databases.

- Unrealistic assumptions about managerial skills: senior managers usually lack the mathematical skills required for applying and understanding real options. Despite literature offering a large number of models for real option analysis, these models generally lack practical implementability. As they are rooted in the financial theory, they entail some hypotheses (e.g., about volatility) that look often opaque and mathematically convoluted to business practitioners (Borison, 2005; Triantis, 2005). According to Lander and Pinches (1998), not only strategic decision makers but even many academics do not have the mathematical skills necessary to use these models comfortably and knowledgeably. On the other hand, as shown by Bowman and Moskowitz (2001), when an option valuation model is selected and used, it is fundamental to understand the hypotheses behind it in order to avoid erroneous conclusions. For more complex investment decisions in real assets, it is also necessary to adapt standard valuation models 
to the specificities of the investment project: again, this requires mathematical skills that are often beyond the capabilities of corporate managers (Bowman and Moskowitz, 2001).

- Loose links to the environment: despite the recognition of uncertainty, most of the current techniques used for real option analysis do not provide clear guidelines for selecting key drivers of change in the external environment and for systematically exploring their likely evolution (Miller and Willer, 2003).

- Timing of exercise: a key difference between real and financial options relates to the clarity of the options' terms. The right to exercise financial options is unambiguous. For instance, the holder of a particular financial option might have the right to buy a given number of shares of a given company at a fixed price at any time before a specified maturity date. But in the case of real options is often unclear how long the holder has the right to exercise the option to invest in real assets. Most of all, it is much more difficult for the holders of real options to update their value as new information becomes available and thereby to decide when the entry or exit should occur. Indeed, many real options are sequential: exercising an option uncovers not an underlying asset but another option. A pharmaceutical company's decision to invest in the next phase of testing of a new drug, for example, depends on the outcomes of earlier tests. Indeed, this feature is characteristic of most R\&D and product-development projects, in which companies make additional investments at critical points (Copeland and Tufano, 2004).

The comparison between the main advantages and disadvantages of scenario planning and real options analysis clearly highlights relevant complementarities and opportunities stemming from the combined use of the two. The advantages of one technique are often specular to the 
advantages of the other. For instance, real options offer the opportunity to evaluate the long-term profits related to each alternative scenario. Similarly, scenarios can help time the decision to exercise real options (Cornelius et al., 2005).

However, so far literature offers little indication and empirical evidence of the way scenario planning and real options analysis might be embedded into each other (Miller and Waller, 2003). Our literature review uncovers just a few empirical studies that recently started to address this issue. For instance, Ram and Montibeller (2013) describe the scenario-based project they adopted for supporting three public sector decision-making instances in Trinidad and Tobago and evaluating the resulting strategic options. Cirjevskis and Baduns (2013) illustrate the joint use of scenarios and real options for maximizing the expected value of a corporate investment decision. Finally, Dortland, Voordijk, and Dewulf $(2012 ; 2013)$ jointly use real options and scenarios for improving real estate management in the Dutch healthcare sector. All these papers provide a clear analysis of the scenario processes that were carried out in their focused studies. However, they do not fully describe how the inputs provided by the scenarios were used for identifying and valuating the strategic options resulting from the scenarios themselves. Most importantly, they do not investigate thoroughly the benefits and pitfalls inherent in the combined implementation of scenarios and real options.

Our paper builds upon the work of previous scholar in order to explore how to bridge the gap between the qualitative approach of scenarios and the quantitative approach of real options. More specifically, we explore how we can use real options in order to quantify the qualitative insights and information resulting from intuitive (deductive or inductive) scenarios. We ask: whether and how can we integrate scenario planning and real options in order to overcome the limitations of these techniques and enhance their benefits? Given the emphasis on organizational 
learning as the main advantage benefit of scenarios, we aim at investigating in particular the relationship among scenarios, real options, and learning skills (de Geus, 1997; van der Heijden et al., 2012).

The remaining of the paper is structured as follows. In the next section we describe our methodological framework for seamlessly integrating real options into scenarios. Then we exemplify this framework by describing its concrete application in the case of a major technology investment decision of a real biotech company. One of the authors was directly involved in this decision: the findings of this paper thereby are based on the collaborative research project we undertook. Collaborative research gave us the opportunity to design and test our methodological framework (Adler et al., 2003; Greenwood and Levin, 1998). Finally we discuss the main benefits and limitations of our integrated method to scenario planning and real option analysis. By doing so, we relate our findings with mainstream literature on scenario planning and real options analysis and we point out future research avenues for their use.

\section{Embedding real options into scenarios: combining the pay-off method and}

\section{the deductive approach}

Many different models and algorithms have been introduced to help strategic investment decision makers evaluate real options. Among these models, on the basis of our empirical experience and research efforts we decided to focus on the pay-off method for real option analysis - recently proposed by Collan et al. (2009) - and to integrate it with the deductive (2x2 matrix) approach to scenario planning.

The merit of the integrated approach we propose in this paper is appealing. On the one hand, scenario planning enables decision makers to identify key drivers of change in their 
external environment. Mostly important, scenarios help decision makers formulate hypotheses regarding the future value of these drivers of change. On the other hand, the pay-off approach help decision makers understand the impact of drivers of change on the organization, by calculating the value of the options to either invest or defer or not to invest. In particular, the pay-off method we illustrate in this paper is quantitative robust but, at the same time, easy enough to be managed by practitioners without a deepen knowledge of econometric models. In this way, the combined methodology we propose not only provides reliable outcomes with regard to the valuation of real options, but most of all enhances the capability of organizations to learn from scenarios.

\subsection{The Pay-off method for real options valuation}

The recently developed pay-off method has the potential to offer a very interesting insight into the field of decision-making, due to the intuitive logic and the simple math underlying its development (Collan et al., 2009).

The method utilises fuzzy sets to determine the possibilistic, as opposed to the probabilistic, expected value of a given investment project. A fuzzy set is a class of elements with a continuum of grades of membership ranging between zero and one. This distribution simplifies reality and assigns the highest degree of possibility (1=fully possible) to the "base" case (or the middle case) and the lowest (approaching 0) degree of possibility to the minimum and maximum values of the distribution. Thus the result is a triangular fuzzy distribution that can be used as the fuzzy distribution of returns on the investment (hence, the pay-off distribution). 
The pay-off method derives the real option value from the pay-off distribution of the project's DCF, which is treated as a fuzzy set. The pay-off distribution has been originally created by using three discounted cash flow scenarios:

1. A 'worst' case scenario, based on the lowest credible estimates for cost and benefits;

2. A 'best' case scenario, based on the highest credible estimates for cost and benefits;

3. A 'base' scenario, based on an intermediate outcome, where cost and benefits are neither maximised nor minimised.

The pay-off method will not consider outcomes outside the worst case and the best case scenarios, therefore the values included define the pay-off distribution of the project's discounted cash flows, which is treated as a fuzzy set. This fuzzy set (A) is defined by three values: 'a' (the best-case scenario DCF), ' $\alpha$ ' (the difference between the worst-case and the base scenario DCF) and ' $\beta$ ' (the difference between the best case and the base scenario). The area between a- $\alpha$ represents the distribution of all possible negative DCF values while the opposite side, between 0 and $\mathrm{a}+\beta$, shows the distribution of positive DCF values. $\mathrm{E}(\mathrm{A}+)$ is the mean value of the expected DCFs of the project, based on the application of fuzzy logic and fuzzy numbers for the creation of the possible pay-off distribution (Collan et al., 2012). The highest possibility (fully possible) is assigned to the central case and the lowest (near-zero) possibility to the minimum and maximum values of the distribution. The resulting triangular fuzzy distribution (A) is equivalent to the fuzzy DCF of the project.

In essence, the pay-off method assigns by default a degree of possibility to the three scenarios representing the three limits of the valuation: base case (fully possible), worst case and best case (virtually impossible). The option value is the positive fuzzy mean of the three limits, 
given by the base case plus the relative distance between the worst and best case. If the distance between the worst case and the base case is higher than the distance between the best and the base case, the option value will be lower than the base case. If the distance between the best and the base case is higher than the distance between the base case and the worst case, the option value will be higher than the base case.

By using the fuzzy distribution, essentially the pay-off method allows to calculate the value of a real option without the need to estimate the dispersion of returns, i.e. the volatility of future cash flows. As we highlighted in the previous section with regard to the main weaknesses of the traditional methods used for real options analysis, volatility is a critical driver of option value in the Black-Scholes model, but it proved to be extremely difficult to estimate for real (nonfinancial) option. The volatility in project value is usually derived via Monte Carlo simulations (Cobb and Charnes, 2004), although sometimes the volatility of the first period's cash flows are preferred (Damodaran, 2005); some analysts substitute a listed security as a proxy, using either its price volatility (historical volatility), or, if options exist on this security, their implied volatility (Borison, 2005). Regardless of the level of sophistication of the method used, the estimate of volatility for projects whose returns are not daily traded is subject to a degree of approximation which represents a major threat to the application (and understanding by practitioners) of the Black-Schole's model to real options. The opportunity offered by the pay-off method to assign a predetermined degree of possibility, rather than probability, to project returns definitely represents a major contribution to the management understanding of uncertainty and its impact on capital investment decisions. When informed with the same inputs, the options calculated with the most sophisticated algorithms and the simple pay-off method seem to converge to almost identical values (Favato et al, 2015). 
Depending on the sign of the base case (positive or negative) and the sign of its relative distance from best and worst scenario, the real option value can be calculated as shown below:

$$
\begin{aligned}
& E\left(A_{+}\right) \\
& =\left\{\begin{array}{lr}
a+\frac{\beta-\alpha}{6}, & \text { if } 0<a-\alpha \\
\frac{(\alpha-a)^{3}}{6 \alpha^{2}}+a+\frac{\beta-\alpha}{6}, & \text { if } a-\alpha<0<a \\
\frac{(\alpha+\beta)^{3}}{6 \beta^{2}}, & \text { if } a<0<a+\beta \\
0, & \text { if } a+\beta<0
\end{array}\right. \text { 'some positive NPV; negative peak' }
\end{aligned}
$$

The real option value calculated from the fuzzy DCF is the possibilistic mean value of the fuzzy DCF values $\mathrm{E}(\mathrm{A}+)$ multiplied by the positive area of the fuzzy DCF over the total area of the fuzzy DCF.

$$
\text { Real option valuation }=\frac{\int_{0}^{\infty e} A(x) d x}{\int_{-\infty}^{\infty 00} A(x) d(x)} E\left(A_{+}\right)
$$

In this equation $\mathrm{A}$ represents the fuzzy $\mathrm{DCF}, \mathrm{E}(\mathrm{A}+)$ is the possibilistic mean of the positive area of the pay-off distribution, $\int_{0}^{\infty} A(x) d x$ is the positive area of the pay-off distribution and $\int_{-\infty}^{\infty} A(x) d(x)$ is the whole area of the pay-off distribution. This method of calculation is aligned with the real option valuation logic, which implies that management will interrupt or modify a project when its pay-off becomes negative. 
Figure 1: Triangular distribution of the fuzzy set $A$

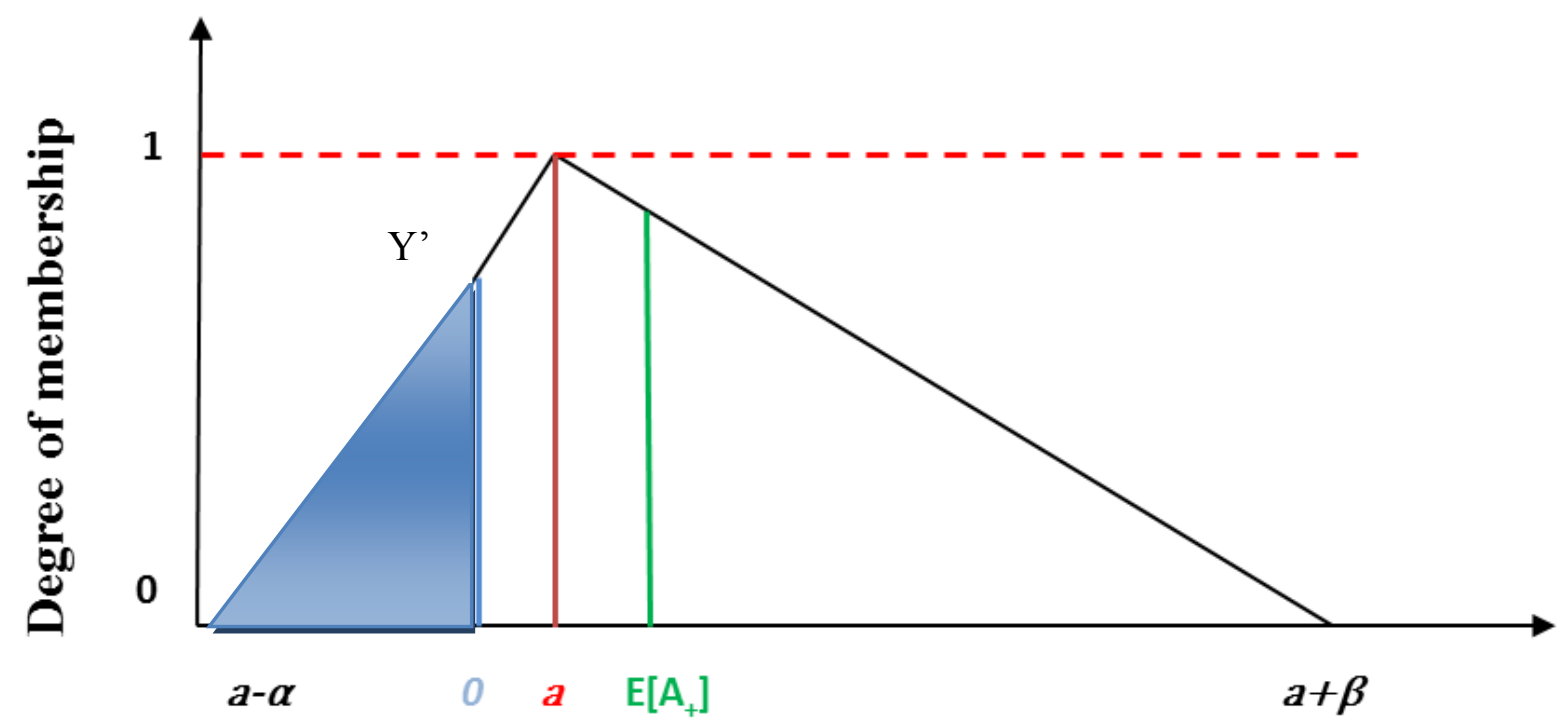

Due to the triangular distribution of the fuzzy set $A+$, the positive value of its fuzzy mean $E(A+)$ can be simply obtained by calculating the negative area (blue triangle) as a percent of the total area of the triangle $a-\alpha ; 1 ; a+\beta$. This can be easily obtained without the use of integral calculation. The missing value (Y' of the apex of the blue triangle) can be obtained by calculating the linear equation of the line defined by two points: $\mathrm{X}=\mathrm{a} ; \mathrm{Y}=1$ and $\mathrm{X}=\mathrm{a}-\alpha ; \mathrm{Y}=0$. Then we have to solve the linear equation for $\mathrm{X}=0$ to obtain the $\mathrm{Y}$ value of the apex of the blue triangle ( $\mathrm{Y}^{\prime}$ in Figure 1$)$. Now the negative portion of $\mathrm{E} A(+)$ can be easily calculated as (a- $\alpha \mathrm{x}$ $\left.\mathrm{Y}^{\prime}\right) / 2$. The negative value as a percent of total can be obtained by simply dividing the area of the blue triangle by the total area of the fuzzy set $A(a-\alpha+a+\beta / 2)$, and then the positive percent value of $\mathrm{E}(\mathrm{A}+)$ by subtracting the negative percent from 1 . If we apply the last percent value to the calculated $\mathrm{E}(\mathrm{A}+)$, the option value is obtained without the use of integral calculation: this can represent a great advantage in terms of diffusion of the payoff model across all level of management, as, contrary to the Black-Scholes model, the mathematical hurdle is quite minimal. 
As we are going to show and emphasize hereafter, the relevance of the pay-off method to management practice is related to its intuitive and visual nature, allowing its application, not only its underlying logic, to be achieved by practitioners.

\subsection{Embedding the pay-off method into the deductive approach of scenarios}

A clear commonality between the pay-off method for option valuation and the scenario methodology is their theoretical underpinning: both methods emphasize the possibilistic, as opposed to the probabilistic, future development of the business environment of the organization (and thereby the possibilistic development of the outcomes inherent in a given strategic investment decision).

Among the different approaches to scenario building, this seems to follow in particular in the domain of the deductive approach. This requires identifying the two most critical drivers of change that are able to affect the outcomes of a given strategic investment decision. As we formulate alternative (opposite) hypotheses with regard to their future pattern of evolution, these two most critical drivers of change become the axes of a 2 × 2 scenario matrix (see Figure 2).

For the sake of simplicity, we generically name these key drivers of change as "Driver A" and "Driver B" and we assume them to have either the most favourable or the most unfavourable evolution for the organization. Clearly, the resulting Scenario 1 is likely to maximize the financial return of the investment decision for the organization while Scenario 3 is likely to bring the most negative outcomes. 
Figure 2: Structure of a 2 x 2 scenario matrix

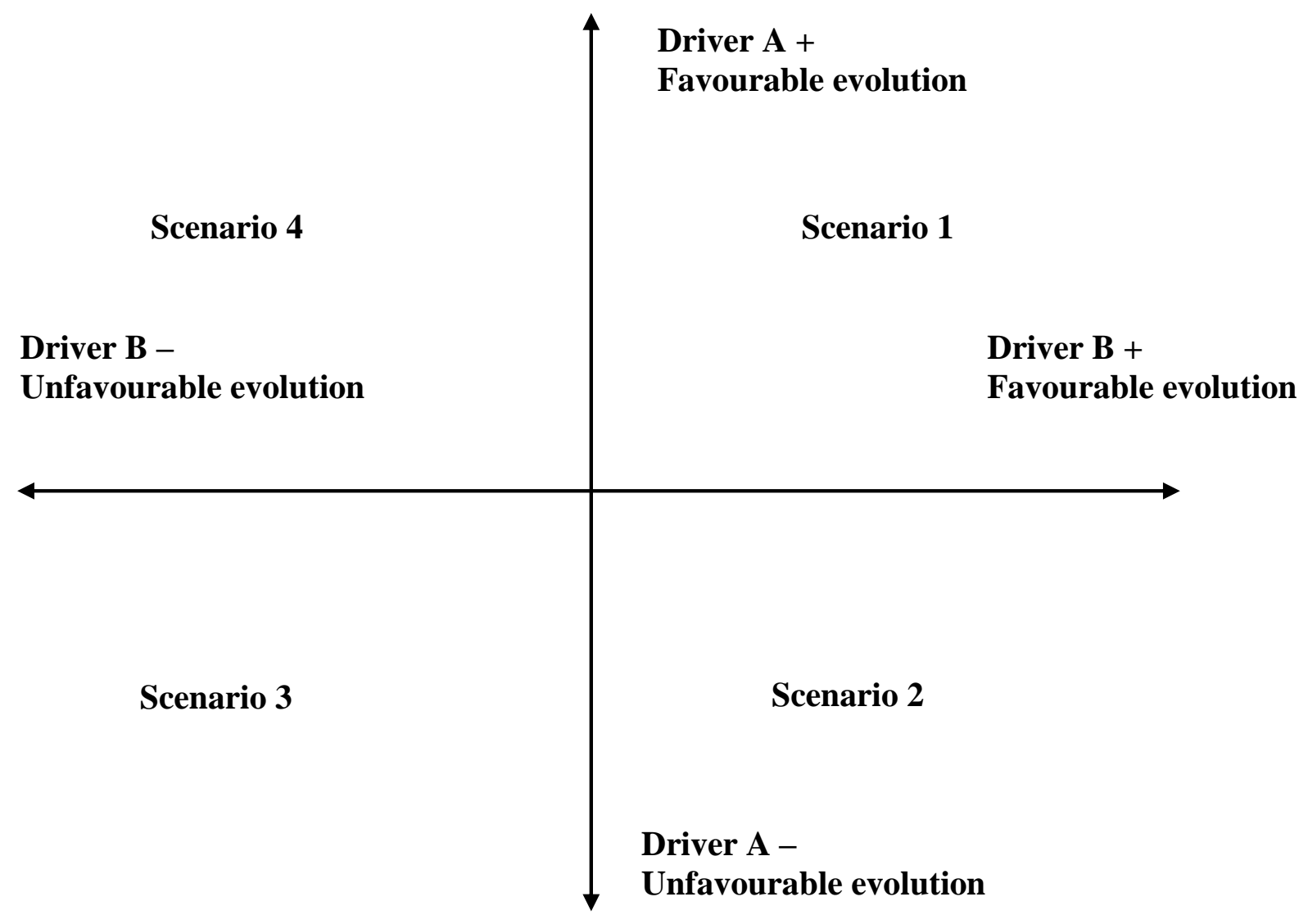

The pay-off method might be seamlessly embedded in the $2 \times 2$ matrix (see Figure 3 ). This matrix defines four scenarios with considerably different impact on project's financials.

The "double negative" scenario (i.e., scenario 3 of Figure 2) is associated with the lowest, expected DCF, hence it is likely to represent the "worst" case input to the pay-off valuation model. The "double positive" scenario represents instead the "best" case scenario underpinning the pay-off method, as it is based on the highest credible estimates for revenues and the most favourable expectations for cost. Finally, the "base" scenario (i.e., the one based on an 
intermediate outcome, where cost and benefits are neither maximised nor minimised), might be represented instead by either the "positive-negative" scenario (i.e. scenario 4 of figure 2 ) or the “negative-positive scenario (i.e. scenario 2) - depending on the different impact of the key drivers (variable A and variable B) on the future outcomes (NPV) of the strategic investment decision. If the relative probability $(1-p)$ of scenario 2 (p') versus scenario 4 (p') to occur is known, then the input to the "base" case can be obtained by calculating a probability weighted mean of the two discounted cash flows:

$$
\text { 'base case' DCF = DCF scenario } 2(1-\mathrm{p} \text { '’ })+\text { DCF scenario } 4(1-p \text { ') }
$$

If the relative probability rates are unknown, then the mean value of the DCFs stemming from scenario 2 and scenario 4 will be an acceptable approximation, as we assume the two scenarios will share the same degree of possibility (full possibility $=1$ ) in the fuzzy distribution of project's returns underlying the pay-off model. 


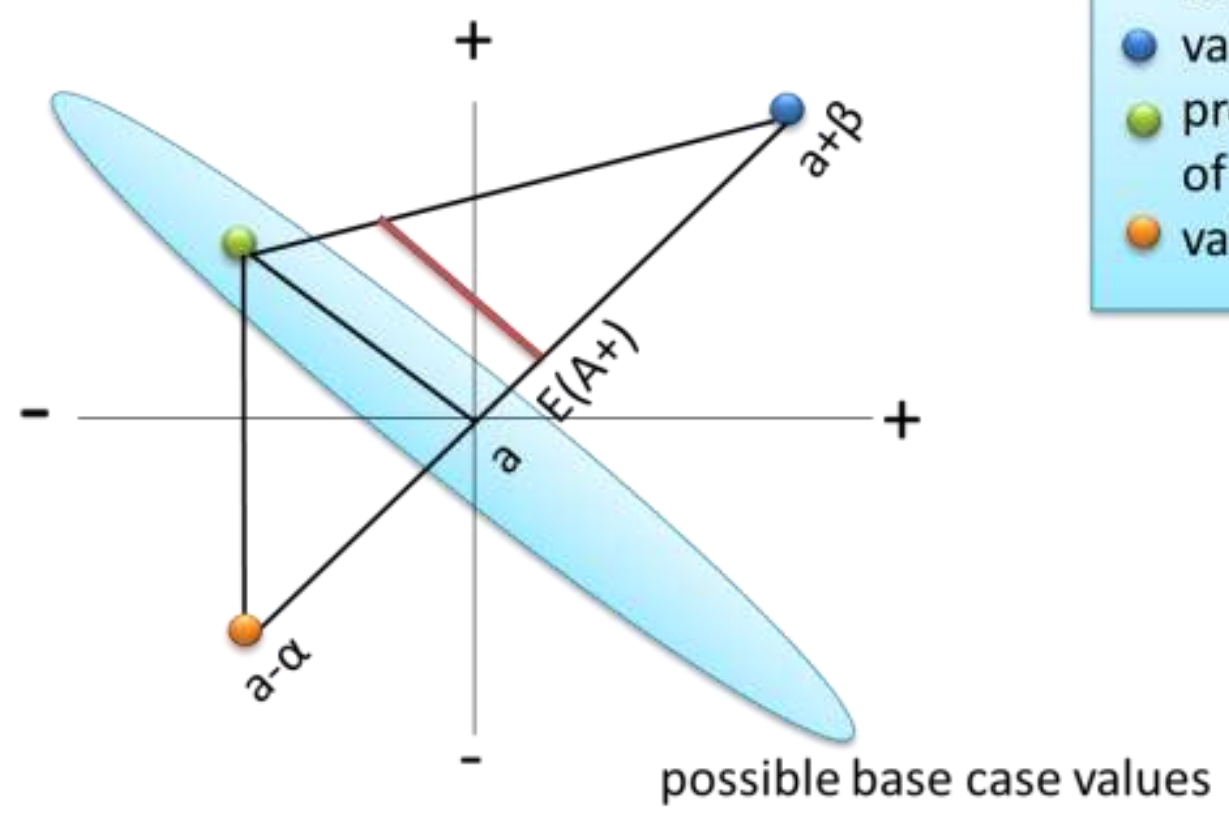

Legend:

value of best case probabilized value of base cases value of worst case

To illustrate this integrated approach, a business case will be illustrated in details. This case relates to $R \& D$ investments in the biotechnology industry: more specifically, in the field of anticancer compounds. Pharmaceutical R\&D is an ideal field for illustrating the application of real options, because in this industry long term profits are maximised by a series of discrete stop/go decisions in clinical research and product development: such discontinuities can create significant uncertainty in the value of project assets. More specifically, each discontinuity creates the option to either invest or defer or abandon the investment. 


\section{Illustrating the combined use of the pay - off method with the $2 \times 2$ scenario method: the case of IDEa-001}

\subsection{Background: the three phases of new drugs development}

The development of anticancer compounds requires different phases. The first phase (Phase I) consists in discovery and preclinical testing, where specificity of antitumor activity and toxicity are initially tested in animal models. Subsequently, Phase I involves testing in human volunteers to identify the toxicities and the maximum tolerated dose in early clinical trials. After phase I, in the second phase (Phase II) studies are carried out in patients of selected tumor type to estimate efficacy compared to historical control and confirm optimal therapeutic dosage (Narang and Desay, 2009). Finally, in the third phase (Phase III) larger studies are aimed at head-to-head comparison of the drug in development with the then-best-available therapy.

As a drug candidate progresses through the Phase I studies in humans, a reverse funnel of increasing patient exposure to the drug becomes necessary. Phase II studies are carried out in a small group of patients with a specific tumor type to determine anticancer efficacy and to define the therapeutic window of the compound. To avoid exposing patients to inactive compounds, these clinical trials use statistical tools to interrupt studies where the in-process data indicate low probability of success. Phase III trials are conducted in a much greater number of patient volunteers of the selected tumor type with prospective and randomized evaluation against the then-available best-possible therapy for the disease, regarded as the standard-of-care in the specific cancer setting. Phase II studies act as a screen of antitumor efficacy to select the most promising agents to enter the pivotal phase III clinical trials. The demonstration of statistically significant improvement in tumor response in large Phase III clinical studies against the currently 
best-available treatment in a tumor type specific patient population is the ultimate benchmark for regulatory approval and marketing of a novel anticancer agent (Baker and Lindemand, 2001).

The end points for determining the clinical value of novel anticancer drugs represent an evolving subject. Phase III cancer clinical trials focus on one primary end point to provide evidence of clinical efficacy and one or more secondary end points to delineate benefits to the patient, such as reduced side effects.

The probability of a new drug in development to reach the market increases with each successive phase of the $R \& D$ process. The overall probability of regulatory approval for an anticancer experimental drug in early stage of development (preclinical to Phase I) has been estimated to be $36 \%$ The probability of successfully terminate the clinical development and receive its first marketing authorisation improves to approximately 50\%, when the compound reaches the end of phase II clinical development (Di Masi et al., 2013).

These high attrition rates are a major challenge for the industry in the face of demands for increased productivity of research and development. Major pharmaceutical companies are placing significant emphasis on the drive to reduce spiralling R\&D expenditure. The optimisation of stop-go decisions is a strategy aimed exactly at direct and immediate reduction of expenditure.

\subsection{Scenarios and real option analysis: the case of IDEa-001}

The combined scenarios/real options methodology we have presented in the previous sections was applied and tested in the case of a real stop/go development decision of an experimental anti-cancer drug. In compliance with the governance mandate to restrain from forward looking corporate disclosures, we will assign a fictional name (IDEaTION) to the biotech company 
developing the anticancer experimental drug in development, which will refer to as IDEa-001. The methodology was applied at the end of the pre-clinical phase (Phase I) of development of IDEa-001 to calculate the value of the option to invest at this particular time and to progress to Phase II. It is worth anticipating here that, at the end of this section, the value we obtain through the innovative pay-off method will be compared with the value obtained for the same real option through the traditional Black-Scholes method (Black and Scholes, 1973).

In the early stage of its development, IDEa-001 showed a promising profile for the treatment of Follicular Lymphoma (FL), the commonest single type of low-grade non-Hodgkin lymphoma. It is a slow-growing lymphoma that develops from B lymphocytes (B cells). It is called 'follicular' lymphoma because the abnormal lymphocytes often collect in lymph nodes in clumps that are known as 'follicles'.

FL treatment is characterised by its slow progression and the number of potential relapses over an average 10 year survival time. Hence, there is a clear path of progression in the disease, requiring patients to be treated several times over their expected life. Novel anti-cancer drugs receive clear regulatory approvals of when they can be used to treat FL patients: when the disease is diagnosed (so called first line treatment), when relapsed patients do not respond anymore to first line treatment (second line) and when patients do not respond to the first two lines of approved treatment (the third line treatment option). It is normally very difficult for a new treatment to challenge the established standard of care, so the logical market progression for IDEaTION will be to focus initially on third- and second-line treatments.

At the end of the Phase I, dose finding studies with IDEa-001 have shown a proof-ofprinciple evidence of clinical efficacy and safety in difficult-to-treat patients. However, data collected so far do not have a statistical power to infer clinical superiority or better efficacy 
compared to the standard of treatment. Moreover, all data have been compared to historical controls, since no comparative, randomised clinical trial has been initiated yet. More data on efficacy (which relates to response rate for oncology drugs) and safety (which relates to incidence of severe, life threatening side effects), i.e. the two main drivers of future sales and profits for a new drug, are needed in order to make an informed decision about the opportunity to invest or not in the further development of IDEa-001. Efficacy and safety are indeed the two main causes of failure in clinical stage drug development, determining respectively 48 and $31 \%$ of the total decisions to abandon the development of an investigational drug (Hay et al., 2014).

\subsubsection{Applying the $2 \times 2$ scenario matrix to the case of IDEa-001}

The $2 \times 2$ matrix reported in Figure 4 describes the four possible scenarios for the development of IDEa-001 at the end of Phase II clinical trials. The four scenarios resulted from the following safety- and efficacy-related strategic issues.

The oncologists managing patients with Follicular Lymphoma face a very difficult decision, as controversies exist regarding the balancing of efficacy and safety in the treatment decision algorithm. In particular, clinical efficacy is measured in terms of percentage of treated patients in complete remission (CR), defined as the disappearance of all signs of cancer in response to the treatment. (This does not always mean the cancer has been cured.) Contextually, clinical researchers grade toxicity from 1 to 4 . Safety is measured in terms of prevalence of GRADE3 and GRADE4 side effects: grade 1 is mild and grade 4 is serious, threatening life or requiring hospitalisation.

Each quadrant of the matrix is defined through the data available in extant literature on the efficacy and safety of the "standard of care", that is the anticancer drugs currently approved for 
the treatment of Follicular Lymphoma in the relative cohort of patients (e.g. second line or third line). The clinical and toxicological profile of IDEa-001 will fall into one of the four quadrants, once the development is concluded. More precisely, at the end of the next development phase (Phase II) the outcomes of clinical trials will provide a proof of principle of the efficacy and safety of the new compound compared to the standard of treatment. At the end of the clinical development (Phase III), it will be finally possible to gain definitive evidence of either the superiority or inferiority of IDEs-001 vs. the standard of care. In other words, the $2 \times 2$ scenario matrix graphically provides a map of the potential competitive advantage of IDEa-001 compared with current treatment options.

At the time of the case study, the standard therapeutic choice in 2nd and 3rd line treatment of relapsed FL patients was chemo-immunotherapy, e.g. Rituximab-based therapy (Dreyling et al, 2011). ${ }^{3}$ Data from earlier clinical trials on Rituximab-based chemotherapy reported 30 to $40 \%$ of complete remission and 40\% of toxicities $\geq$ GRADE3 (Maloney et al., 1997; Forstpointner et al, 2004). The efficacy and the safety of Rituximab-based therapy precisely define the boundaries of four alternative and non-competing scenarios for the possible outcome of a new experimental drug.

A novel treatment of FL must demonstrate an efficacy significantly higher than $40 \% \mathrm{CR}$ and an incidence of toxicities $\geq$ GRADE3 significantly lower than $40 \%$ to be elected as treatment of choice in $2^{\text {nd }}$ line FL ('best case' scenario: upper-right scenario of Figure 4). An efficacy rate higher than Rituximab but a prevalence of side effects $\geq$ GRADE3 significantly higher than $40 \%$ would limit the use of the new treatment to $3^{\text {rd }}$ line - specifically to patients in good performance status who could tolerate the severity of the expected toxicities (upper-left scenario of Figure 4). A remission rate significantly lower than $40 \%$ coupled with an improved level of safety (less

\footnotetext{
${ }^{3}$ Rituximab (Rituxan ${ }^{\circledR} /$ Mabthera $\left.{ }^{\circledR}\right)$ is an anti-CD20 antibody developed and marketed by Roche AG.
} 
than $40 \%$ of $\geq$ GRADE3 toxicities) would relegate the use of the novel treatment to $3^{\text {rd }}$ line patients in a poor performance status, who cannot tolerate a Rituximab-based chemotherapy (bottom-right scenario of Figure 4). As we assumed that the two scenarios had the same degree of possibility, the 'base case' was then calculated as the average between the upper-left scenario and the bottom-right scenario. Quite understandably, a novel treatment with an efficacy and safety profile significantly worse than the available treatment options would offer no clinical benefits to FL patients, hence its development should be discontinued ('worst case' scenario: bottom -left scenario of Figure 4).

The development would progress to Phase III only in case that at least one of the major drivers of change (i.e. safety or security) would show the possibility to be marginally superior to the current standard of treatment, even though still compared to historical controls. In the case of the "negative - negative" scenarios clearly IDEa-001 will not be launched into the market and thereby it will not generate any return. The uncertainty embedded in Phase II data is still comparable to the flip of a coin: on average, $50 \%$ of experimental oncology compounds which reach the end of Phase II fail later on to complete their development and to file for marketing authorisation. 
Figure 4: Possible scenarios of the IDEa-001 development at the end of Phase II

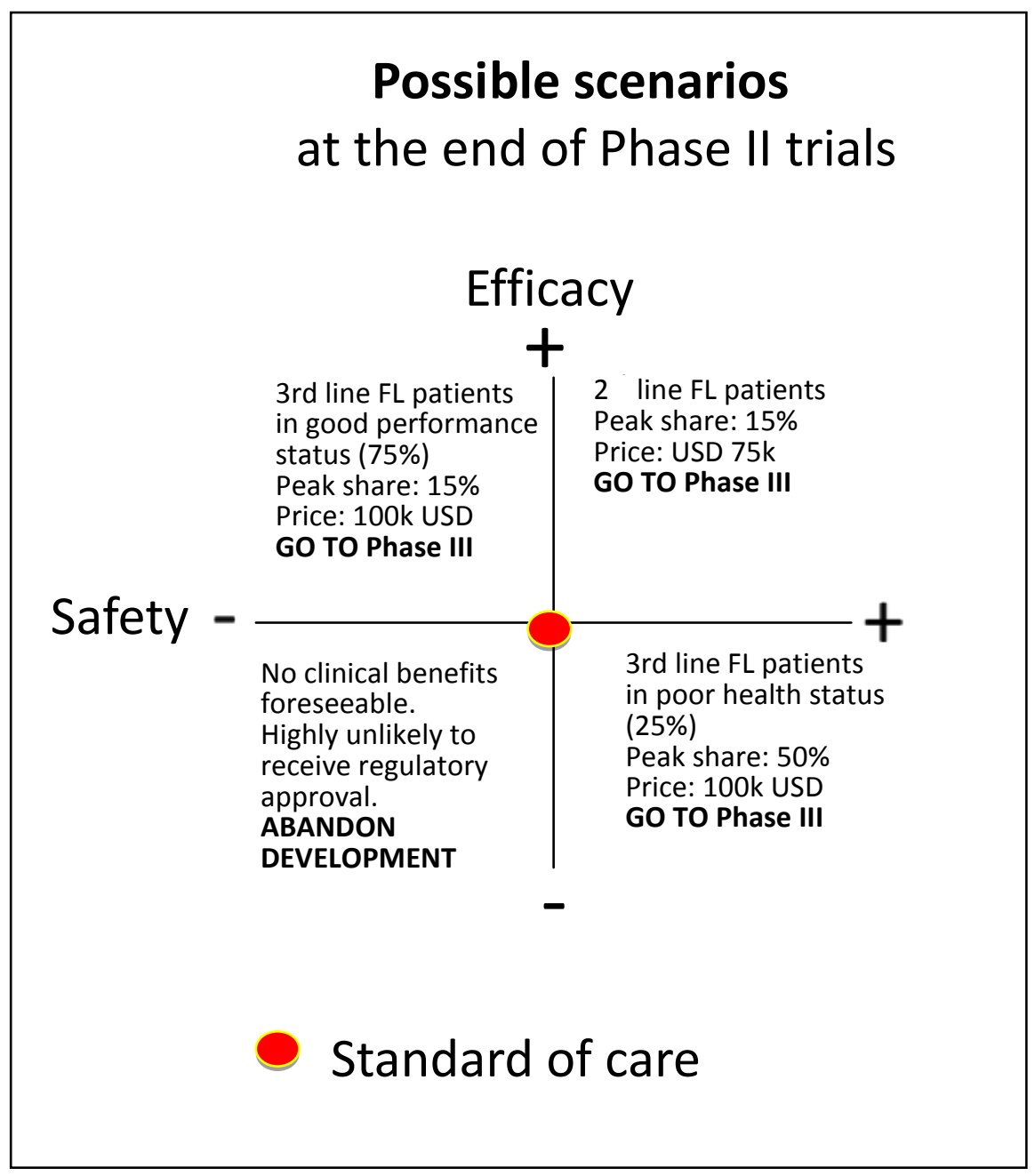

The dilemma faced by the IDEaTION management is daunting: should they invest an estimated \$10.2 million now (end of Phase I) to complete the Phase II and get enough information to make an informed stop/go decision with regard to the development of Phase III? With the odds of successful Phase III development still equal to a coin toss, would it be worthy to invest additional $\$ 44.0$ million, the estimated cost of the late-stage clinical development of IDEa-001?

This decision is critical for the survival of IDEaTION, whose only asset is IDEa-001. The uncertainty can be reduced by framing this decision as a real option: the $\$ 10.2$ million should be 
seen as the price of the option to proceed to late-stage clinical development (execution of Phase III). If the option value is higher than the cost of Phase II development (option price), IDEaTION should invest, otherwise the development of IDEa-001 should be stopped now.

As mentioned before, the pay-off method can reduce the uncertainty, but it cannot offset it completely. By probabilising the discounted cash flows stemming from the three 'go' scenarios

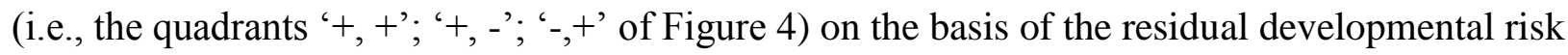
at the end of Phase II (50\% risk of failure) and by considering the residual cost of development of Phase III as a fixed cost, the pay-off method generates a fuzzy-distribution of possible discounted cash flows, whose mean is the value of the real option. A significant management effort should be dedicated to a credible valuation of the three 'go' scenarios.

\subsubsection{Applying the pay-off model for evaluating the option to develop IDEa-001}

A specific illustration of the inputs chosen to inform the DCFs is reported in Table 1. 
Table 1: inputs to the DCFs stemming from the $2 \times 2$ scenarios of Figure 4

\begin{tabular}{|c|c|c|c|c|c|}
\hline $\begin{array}{l}\text { INPUTS TO Discounted Cash Flow } \\
\text { (DCF) model }\end{array}$ & $\begin{array}{l}\text { WORST } \\
\text { SCENARIO }\end{array}$ & $\begin{array}{c}\text { BASE CASE } \\
\text { safety -; } \\
\text { response rate + }\end{array}$ & $\begin{array}{l}\text { BASE CASE } \\
\text { safety+; } \\
\text { response rate } \\
-\end{array}$ & $\begin{array}{c}\text { BEST } \\
\text { SCENARIO }\end{array}$ & SOURCES \\
\hline $\begin{array}{l}\text { Follicular Lymphoma (FL) patients in US } \\
\text { and } 5 \text { major EU Countries }\end{array}$ & 36,727 & 36,727 & 36,727 & 36,727 & $\begin{array}{l}\text { Globocan IARC WHO } \\
\text { www.globocan.iarc.fr }\end{array}$ \\
\hline Annual growth rate & $1.5 \%$ & $1.5 \%$ & $1.5 \%$ & $1.5 \%$ & $\overline{\text { Globocan IARC WHO }}$ \\
\hline Indication (s) & $\begin{array}{c}\text { Abandon } \\
\text { development }\end{array}$ & Third line & $\begin{array}{l}\text { Third line, } \\
\text { patients in } \\
\text { poor status }\end{array}$ & Second line & IDEaTION strategic assessment \\
\hline Patients treated (\% of total FL patients) & - & $10.5 \%$ & $3.5 \%$ & $33 \%$ & IDEaTION estimate \\
\hline IDEa-001 peak share & - & $15 \%$ & $50 \%$ & $15 \%$ & IDEaTION estimate \\
\hline First approval \& launch & - & Year 3 & Year 3 & Year 3 & IDEaTION estimate \\
\hline Patent expiration & - & Year 16 & Year 16 & Year 16 & IDEa-001 IND filing \\
\hline Net effective price per patient & - & $\$ 100,000$ & $\$ 100,000$ & $\$ 75,000$ & $\begin{array}{l}\text { IDEaTION targets based on the inverse } \\
\text { correlation between incidence and price }\end{array}$ \\
\hline Probability rate of marketing approval & - & $50 \%$ & $50 \%$ & $50 \%$ & $\begin{array}{l}\text { Global Data attrition analysis } \\
\text { www.globaldata.com }\end{array}$ \\
\hline R\&D investment to complete PII & $\$ 10.2$ mill & $\$ 10.2$ mill & $\$ 10.2$ mill & f10.2 mill & $\overline{\text { IDEaTION estimate }}$ \\
\hline $\begin{array}{l}\text { Incremental R\&D investment to } \\
\text { complete development }\end{array}$ & - & \$44 million & \$44 million & $\$ 44$ million & IDEaTION estimate \\
\hline Annual cost of pharmaco-vigilance & - & $\$ 2$ mill & $\$ 2$ mill & $\$ 2$ mill & IDEaTION estimate \\
\hline $\begin{array}{l}\text { Annual incremental fixed capital } \\
\text { investments }\end{array}$ & - & $\begin{array}{l}\text { Up to } \$ 2 \text { mill in } \\
\text { Year } 5 ; \$ 1 \text { mill } \\
\text { thereafter }\end{array}$ & $\begin{array}{l}\text { Up to } \$ 2 \text { mill in } \\
\text { Year } 5 ; \$ 1 \text { mill } \\
\text { thereafter }\end{array}$ & $\begin{array}{l}\text { Up to } \$ 2 \text { mill in } \\
\text { Year } 5 ; \$ 1 \text { mill } \\
\text { thereafter }\end{array}$ & $\begin{array}{l}\text { IDEaTION estimates of capital required } \\
\text { to scale-up and to maintain supply after } \\
\text { approval }\end{array}$ \\
\hline Basis for probabilised costs & - & revenues & revenues & revenues & Probability-adjusted revenues \\
\hline Cost of Goods Sold & - & $20 \%$ & $20 \%$ & $20 \%$ & $\begin{array}{l}\text { IDEaTION estimate based on small scale } \\
\text { PI manufacturing costs }\end{array}$ \\
\hline Sales \& Marketing costs & - & $10 \%$ & $10 \%$ & $10 \%$ & Global Pharma: biotech industry average \\
\hline Other operating expenses & - & $5 \%$ & $5 \%$ & $5 \%$ & Global Pharma: biotech industry average \\
\hline Effective tax rate as \% of EBIDTA & - & $35 \%$ & $35 \%$ & $35 \%$ & IDEaTION estimate \\
\hline Discount rate & - & $12 \%$ & $12 \%$ & $12 \%$ & Global Pharma (+4\% illiquidity premium) \\
\hline
\end{tabular}

Although a detailed description of the inputs chosen to inform the discounted cash flows (DCFs) attributed to each scenario is beyond the scope of this paper, it is useful to briefly discuss the main drivers of DCF in the valuation of biotechnology assets (new experimental drugs). The market potential has been derived from epidemiological data available through public sources (mainly Globocan, the World Health Organization database). ${ }^{4}$ Numbers of treated patients, peak share and time to launch were informed by management consensus estimates based on the performance of previous drugs approved for the treatment of Follicular Lymphoma. Expected net selling price has been estimated on the basis of expert opinions, due to the uncertainty correlated with this variable; an inverse correlation between incidence of treated patients and price has

\footnotetext{
${ }^{4}$ www.globocan.irac.fr
} 
determined the choice of a lower price ( $\$ 75,000$ per treated patient) for the second line indication, which could benefit a much larger cohort of FL patients (33\% of total) compared to a third line $(10.5 \%)$ or a third line limited to patients in poor performance status $(3.5 \%)$. A net effective selling price of $\$ 100,000$ per patient was chosen for both the third line indications. Any additional investment in clinical trials necessary to complete the development of IDEa-001 beyond the Phase II was considered to be a fixed cost, while all other costs were considered variable, hence they were probabilised at the same rate used to probabilise revenues. All product costs (manufacturing costs and incremental fixed capital investments, necessary to scale up supply to meet demand) were determined as a percent of revenues, based on preliminary information gathered in early stage development. Period cost estimates (such as general, admin, marketing and other operating expenses) were derived from Global Data, a proprietary database specialised in the biotechnology industry. ${ }^{5}$

An opportunity cost of capital was deducted by the DCF, represented by the returns on a similar investment in the NASDAQ index ( $8 \%$ in 2015). A constant illiquidity premium of four percent points was added to the discount rate to reflect this difference in liquidity with traded equity indexes and make the relative returns comparable (Damodaran, 2006). The total cost of capital was estimated to be $12 \%$ across the DCF period.

Once the discounted cash flows were obtained, we proceeded to the calculation of the real option value embedded in the 4 scenarios, by using the pay-off method (later on this section we compare the results gained through the pay-off method with the ones provided by the BlackScholes algorithm, specifically adjusted for the valuation of non-financial assets).

\footnotetext{
${ }^{5}$ www.globaldata.com
} 
Table 2 reports the main inputs used to inform the pay-off model for the calculation of the real option value of the project (see Figure 5); later on the same inputs were used to inform the Black-Scholes algorithm.

Table 2. Inputs to inform the pay-off (and Black-Scholes) real option pricing model

\begin{tabular}{|c|c|c|}
\hline USD millions & VALUES & Inputs \\
\hline \multicolumn{3}{|l|}{ REAL OPTION VALUATION: PAY-OFF METHOD } \\
\hline \multicolumn{3}{|l|}{$E(A+)=a+\frac{\beta-\alpha}{6}$} \\
\hline Best case: second line treatment & 78.9 & \\
\hline Base case (probabilised): third line treatment & 11.8 & \\
\hline Scenario: safety -; response rate + (non-responsive patients) & 10.9 & $60 \%$ \\
\hline Scenario: safety +; response rate - (poor-status patients) & 13.2 & $40 \%$ \\
\hline Worst case: abandon development & 0 & \\
\hline$a=$ base case (probabilised) & & 11.8 \\
\hline$B=$ best case - base case & & 67.1 \\
\hline$\alpha=$ base case - worst case & & 11.8 \\
\hline$E(A+)$ & & 21.02 \\
\hline Option value $=E(A+)-$ initial investment (cost of Phase $I I=10.2)$ & 10.82 & \\
\hline \multicolumn{3}{|l|}{ REAL OPTION VALUATION: BLACK-SCHOLES METHOD ${ }^{2}$} \\
\hline Volatility (3 month historic volatility IDEaTION share price) & & $40 \%$ \\
\hline Lifetime of the project (years from PII investment decision to patent expiration) & & 16 \\
\hline Annual cost of delay investment (yearv 16 Discounted Cash Flow/Total DCF) & & $5 \%$ \\
\hline Riskless rate (yield 20 year US treasury bond) & & $2.80 \%$ \\
\hline Best case: second line treatment & 30.41 & $33 \%$ \\
\hline Base case (probabilised): third line treatment & 2.82 & $33 \%$ \\
\hline Worst case: abandon development & 0 & $33 \%$ \\
\hline Option value (cost of Phase II embedded in the B-S model) & 10.97 & \\
\hline Difference between Pay-off and BS option value & -0.14 & \\
\hline$\%$ & $-1.3 \%$ & \\
\hline \multicolumn{3}{|l|}{${ }^{1}$ Estimates based on Phase I data } \\
\hline 2 Source: Damodaran (2006) & & \\
\hline
\end{tabular}


A fuzzy pay-off distribution was thus created by using the three 'go' scenarios derived from the IDEa-001's investment in Phase II clinical trials.

Since:

$a-\alpha=0$

all the discounted cash flows are non-negative, as the DCF for the worst case scenario is $=0$ (abandon the project). Thereby E(A+), the possibilistic mean value of the fuzzy distribution of DCF values was calculated as shown below:

$$
E(A+)=a+\frac{\beta-\alpha}{6}
$$

This is the simplest case in the pay-off method, since all values are positive, hence the positive portion of $\mathrm{E}(\mathrm{A}+)$ is equal to $\mathrm{E}(\mathrm{A}+)$.

The option value embedded in the investment decision at the end of Phase I development of IDEa-001 is thus $\$ 21.02$ million. As the option price (= cost of Phase II clinical trials) is estimated to be $\$ 10.2$ million, the difference between option value and option price is positive, hence the investment should be done. 
Figure 5: Graphical representation of IDEa-001's real option value of Phase II clinical trials investment

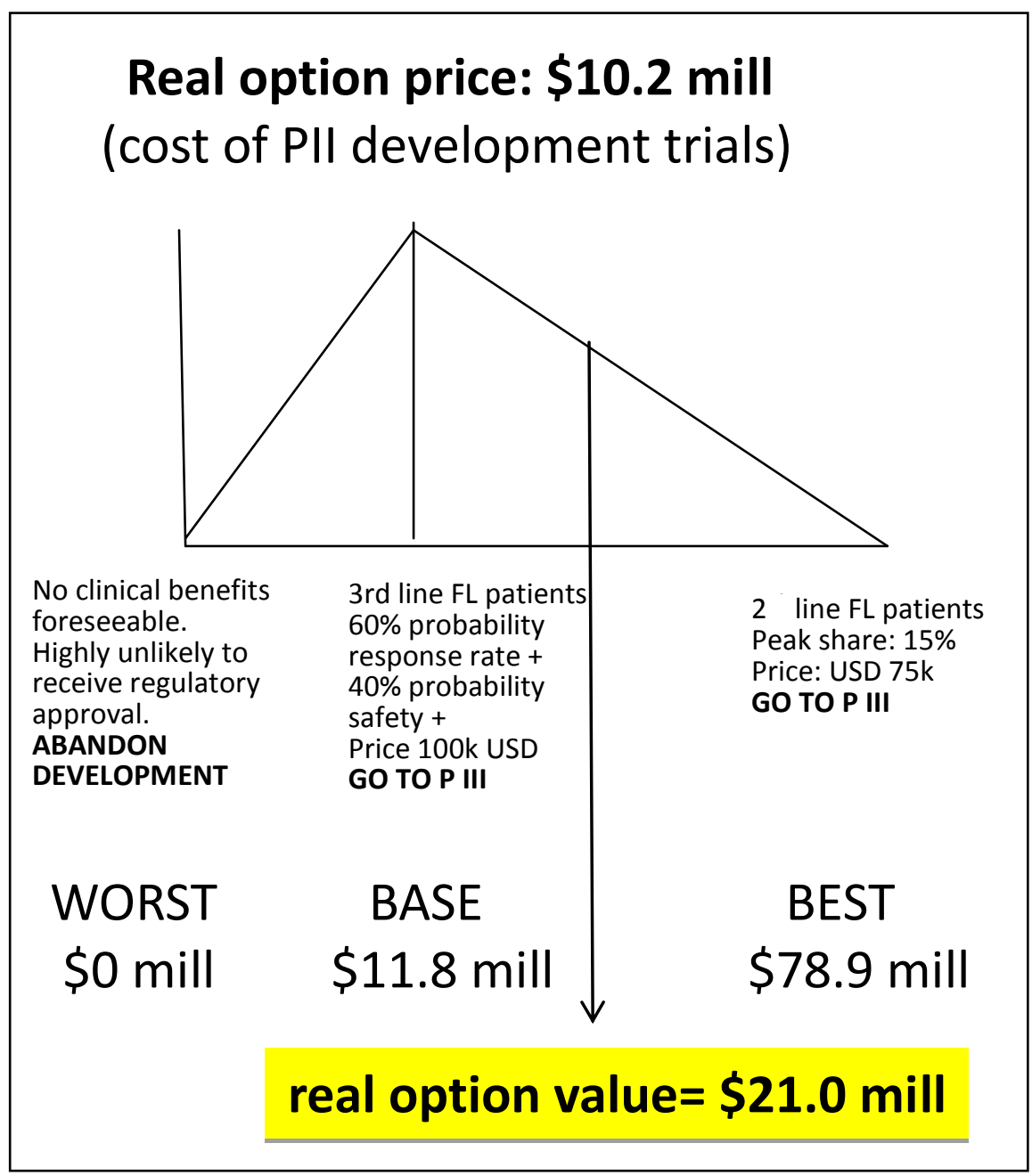

Based on this evidence, the Board of IDEaTION committed $\$ 10.2$ million to continue the clinical development of IDEa-001, which progressed to Phase II.

What really convinced the management to go ahead with the development of IDEa-001 was not just the positive value per se of the real option embedded in the incremental capital investment. Any experienced manager recognises that the outcomes are based on inputs whose variability is really unpredictable. Any new information about the disease, new treatments or the 
clinical profile of the drug in development can at any moment change the set of assumptions underlying the discounted cash flows. This is essentially related to the undiversifiable risk which drives the returns on the biotechnology sector significantly above the NASDAQ average.

The main reason which led the Board to a "go" decision was the confidence to connect their inputs (the discounted cash flows of the four scenarios) with "possible" mean returns whose distribution could be visualised in the shape of a simple triangle. The intuitive representation of uncertainty about future returns obtained with the pay-off method allowed management to confidently reflect on the key drivers of value embedded in the discounted cash flows, i.e. efficacy and safety, and to blend their mutually exclusive patterns of evolution (in the different scenarios) into a coherent and comprehensive measure of value: the real option. The pay-off model established a direct and immediate connection between the main drivers of change (efficacy and safety) and the four possible scenarios leading to the option value of IDEa-001 at the time of the investment decision (end of Phase I). In order to maintain this link as unequivocal and direct as possible, a decision was made to use a relatively uncomplicated and static methodology to calculate the free cash flows resulting from each outcome of clinical development. A more dynamic approach, based on MonteCarlo simulations, probability functions or Bayesian models would have definitely improved the statistical validity, hence the reliability of the free cash flow projections, which are the key drivers of the real option value in the pay-off method. The static approach to the estimation of free cash flow remains a main limitation of our methodology, although its intuitive simplicity proved to be the most significant benefit to the managers involved in the application of the pay-off technique. This simplicity allowed decision makers to easily discuss and grasp the value implications of the alternative patterns of evolution of efficacy and safety in the four scenarios. 
One question still needs to be addressed: does the simplification of volatility calculation provided by the pay-off method lead to real option values similar to the ones calculated with the traditional Black-Scholes algorithm? In other words, is the pay-off method accurate enough to support complex capital investment decisions?

\subsubsection{IDEa-001 and real option valuation: comparing the pay-off method with the Black-}

\section{Scholes model}

Traditionally, the option pricing algorithms used for the valuation of R\&D projects in the pharmaceutical industry have been based on the Black-Scholes model (Trigeorgis, 1996). To test the credibility of the real option value calculated as the mean of the fuzzy distribution of possibilistic pay-offs, we thus calculated the same value by using the Black-Scholes algorithm (Damodaran, 2006).

A specific illustration of the inputs chosen to inform the Black-Scholes models is reported in Table 2. The three real option values obtained by informing a Black-Scholes algorithm with the three allowable scenarios of IDEa-001's expected DCF at the end of Phase II were the following:

Worst scenario:

Base scenario (average between scenarios 2 and 3) $\$ 2.82$ mill (33\% probability)

Best scenario: $\$ 30.41$ mill (33\% probability)

\section{Equal probability value $\quad \$ 10.97$ mill}


The basic data used as inputs for the three scenarios in the case of the application of the BlackScholes method obviously differs from the case of the pay-off method: while the real option value in the Black-Scholes algorithm is the result of a partial derivative equation (the Ito's

lemma) ${ }^{6}$ based on current asset price (the cost of Phase II development, \$10.2 million) increased over time by its implied annual volatility, in the pay-off method we simply input the discounted free cash flows (see Table 2). Hence, the option price does not need to be deducted by the BlackScholes option value, while it does from the outcome of the pay-off method. Another relevant difference is represented by the way the real option pricing model accommodates scenarios: while the pay-off method assigns a "possibility" to the four relevant scenarios, the Black-Scholes model treats each scenario individually. To compare the real option prices derived from the two models, we chose to assign an equal probability (33\%) to the values derived from the three Black-Scholes options and to derive an equally weighted mean of the three scenarios. The real option value obtained ( $\$ 10.97$ million) was absolutely comparable to the option value calculated with the pay-off method ( $\$ 10.82$ million), showing a negligible difference of $1.3 \%$.

The pay-off method confirmed to be an algorithm to calculate the value of real options at least as reliable as the Black-Scholes model; this empirical observation supports previous scholars' contributions (Favato et al., 2015).

\section{Discussion}

In this paper we aim at expanding our understanding of scenario planning and real options analysis, while making their use among practitioners more profitable and easy. Our main contribution, in particular, is to integrate scenarios and real options so as to overcome - or at

\footnotetext{
${ }^{6}$ Kyosi Ito (1944) Stochastic Integral. Proc. Imperial Acad. Tokio 20, 519 - 524.
} 
least mitigate - their main limitations. Based on the feedback we gained from the case of IDEA_001, we consider hereafter each one of these limitations (which we pointed out in the previous sections of the paper) and we illustrate the benefits we achieved through our methodological approach.

In the case of scenarios, one of the most relevant weaknesses regards the lack of quantitative data. In the case of real options, one of the main weaknesses regards the ambiguity about the identity and the dynamics of evolution of key drivers of change in the external environment (Miller and Willer, 2003). Our integrated methodology allowed to overcome these limitations by seamlessly exploiting the complementarities between the qualitative nature of scenarios and the quantitative nature of real options. On the one hand, scenarios lay the foundations for identifying and making hypotheses about the future evolution of key drivers of change. On the other hand, the pay-off methods pushed managers to think about the cash flows stemming from each scenario. The hypotheses about the alternative patterns of evolution of drivers of change (e.g., safety and effectiveness in the case of IDEa-001) became the inputs for the application of the pay-off method. Contextually, the pay-off approach quantified the value of drivers of change in the four alternative scenarios so that the latter ones (and thus the "memory of the future" of the managers) became more vivid and understandable. The benefits inherent in the use of quantitative indicators are often emphasized in literature on strategic management (Kaplan and Norton 1993; Tapinos et al., 2005). Indeed, the pay-off method provided strategic decision makers with tangible measures - about future cash flows and profits - that helped them to link each scenario with its financial impact. These measures become clear data and explicit knowledge, which could be easily shared and understood throughout the organization. The combination of the qualitative insights stemming from scenarios and the quantitative data gained 
through real options analysis, definitely improved the learning capabilities of IDEaTION's managers to explore their business environment, select relevant changes and react to these changes. In particular, based on the new information that became available over time about the efficacy and safety of IDEa-001, the managers of the company quickly decided to move from phase 1 to phase 2 and later on to get quoted in the Stock Exchange.

Similarly, the integrated use of real options mitigated the other possible pitfalls of scenarios, i.e. the biases due to dominant managers and the lack of consistency and rigorousness of scenarios themselves. Real options enabled and framed the valuation of the financial impact of key drivers of change: this valuation provided an useful basis for pointing out what drivers of change were actually the most relevant ones - compared with the personal opinions of dominant personalities. What is more, the provision of quantitative data allowed decision makers to better check the rigorousness and internal consistency of scenarios, e.g. by comparing the values of the same driver of change in the different scenarios.

Specifically, the pay-off method we illustrated in this paper proved to be very effective for overcoming some application pitfalls inherent in the traditional financial-based approaches to real option valuation, e.g. the Black-Scholes formula. This is the case of the mathematical and statistical skills managers require for using these traditional approaches: compared with the latter ones, the pay-off method offered a simple and reliable alternative, which exempted the executives of IDEaTION from high-complicated and daunting mathematics. Indeed, the simplification of real option valuation was the core motivation for this paper. Thanks to the payoff method, strategic decision makers should perceive no longer real options as an arcane subject, by seamlessly integrating them with scenarios and finally making a more widespread use of both these tools. 
In particular, the most relevant advantage of the pay-off method regards the issue of volatility. Out of the five inputs necessary to solve the Black-Scholes differential equation, volatility is definitely the most difficult to estimate (Copeland and Tufano, 2004; Triantis, 2005). As it does not require to calculate volatility, the pay-off method is less likely to "frighten" or confuse decision makers - and thereby is less likely to prevent business executive from using real options.

Finally, it is worth noting that, in the case of IDEa-001, the combination of the $2 \times 2$ scenario matrix and the pay-off method provided the analytical framework for a straight process that helped the managers of the company decide when (and whether) they had to invest in the second phase of development of the new drug. As new information about the key uncertainties and drivers of change (e.g. safety and effectiveness of IDEa-001, number of patients, operational costs, price and revenues) became available, managers could quickly update the valuation of the real option related to the new drug and thereby could identify the right time to exercise this option.

In the following Table 3 we sum up: i) the main limitations affecting scenarios and real options (when used separately); ii) the likely benefits stemming from our integrated methodology; and iii) the specific source of these benefits.

Table 3. Combining scenarios with real options: limitations, benefits, and sources of these benefits

\begin{tabular}{|l|l|l|}
\hline \multicolumn{1}{|c|}{$\begin{array}{c}\text { Limitations } \\
\text { (single technique) }\end{array}$} & \multicolumn{1}{c|}{ Benefits } & Source of benefits \\
\hline $\begin{array}{l}\text { Biases (scenarios: Miller } \\
\text { and Waller, 2003) }\end{array}$ & $\begin{array}{l}\text { Quantitative data provide a more objective basis for } \\
\text { identifying the impact of drivers of change on the } \\
\text { organization - and thereby for reaching a consensus on } \\
\text { the most relevant drivers }\end{array}$ & $\begin{array}{l}\text { Real options: } \\
\text { quantitative } \\
\text { approach/data }\end{array}$ \\
\hline
\end{tabular}




\begin{tabular}{|c|c|c|}
\hline $\begin{array}{l}\text { Lack of consistency } \\
\text { (scenarios: Miller and } \\
\text { Waller, 2003) }\end{array}$ & $\begin{array}{l}\text { Quantitative data help to check the internal consistency } \\
\text { of each scenario (e.g., by comparing the value of the } \\
\text { same driver of change in the four alternative scenarios) }\end{array}$ & $\begin{array}{l}\text { Real options: } \\
\text { quantitative } \\
\text { approach/data }\end{array}$ \\
\hline $\begin{array}{l}\text { Lack of quantitative data } \\
\text { (scenarios: Schoemaker, } \\
\text { 1993) }\end{array}$ & $\begin{array}{l}\text { Real options provide quantitative data which enable } \\
\text { managers to turn the narrative of scenarios into the } \\
\text { financial effects of external changes and new events. } \\
\text { The availability of quantitative data enhances the } \\
\text { learning skills of decisions makers, i.e. their } \\
\text { capabilities to select and seize changes in the business } \\
\text { environment }\end{array}$ & $\begin{array}{l}\text { Real options: } \\
\text { quantitative } \\
\text { approach/data }\end{array}$ \\
\hline $\begin{array}{l}\text { Difficulty to value } \\
\text { options in real assets (real } \\
\text { options: Copeland and } \\
\text { Tufano, 2004) }\end{array}$ & $\begin{array}{l}\text { The pay - off method does not require managers to } \\
\text { evaluate volatility (contrary to the case of established } \\
\text { methods like Black-Scholes) }\end{array}$ & Pay-off method \\
\hline $\begin{array}{l}\text { Unrealistic assumptions } \\
\text { about managerial skills } \\
\text { (real options: Krychowski } \\
\text { and Quelin, 2010; } \\
\text { Triantis, 2005) }\end{array}$ & $\begin{array}{l}\text { The pay-off method requires relatively simple } \\
\text { statistical and mathematical skills }\end{array}$ & Pay-off method \\
\hline $\begin{array}{l}\text { Loose links to the } \\
\text { environment (real } \\
\text { options: Miller and } \\
\text { Waller, 2003) }\end{array}$ & $\begin{array}{l}\text { The } 2 \times 2 \text { scenario matrix provides a clear narrative } \\
\text { about drivers of changes and their future dynamics. } \\
\text { Based on these dynamics, managers can clearly link } \\
\text { real options analysis with the likely evolution of the } \\
\text { business environment }\end{array}$ & $\begin{array}{l}\text { Scenarios: } \\
\text { qualitative } \\
\text { approach/data }\end{array}$ \\
\hline $\begin{array}{l}\text { Timing of exercise (real } \\
\text { options: Copeland and } \\
\text { Tufano, 2004) }\end{array}$ & $\begin{array}{l}\text { The } 2 \times 2 \text { scenario matrix combined with the pay-off } \\
\text { method allows managers to get a flexible analytical } \\
\text { framework. Managers can easily update the valuation } \\
\text { of real options, so making more informed decisions } \\
\text { about when they should exercise these options }\end{array}$ & $\begin{array}{l}2 \times 2 \text { scenarios } \\
\text { matrix combined } \\
\text { with the pay-off } \\
\text { method }\end{array}$ \\
\hline
\end{tabular}

Despite these benefits, the case of IDEa-001 highlighted some shortfalls that prevented our methodological approach from fully overcoming the traditional limitations of scenarios and real options.

First, the quantification of the future values of drivers of change still strongly depended on the knowledge and opinions of the experts and managers involved in the scenario process. On the one hand, some key environmental forces were quite precise and predictable, like demographics. On the other hand, for many drivers there was a lack of reliable quantitative inputs and thereby the future evolution of these drivers was much more difficult to quantify: that was the case for 
instance of customers' attitude and acceptance, or future regulatory limitations and financial expenditures of national health systems. Indeed, real options helped managers to reflect upon the value of the main drivers of change and find a consensus which could reconcile their different assumptions. However, the value of some variables (like the future budgetary constraints of the national health systems in the alternative scenarios) was definitely subjective: our methodological approach should be meant thereby as a framework which enhances the cognitive benefits of scenarios and real options, rather than the reliability of the quantitative data (i.e., future values of drivers of change) provided by the scenarios themselves.

Second, despite the simplicity of the pay-off method compared with traditional approaches for real option analysis, in the case of IDEa-001 it was very difficult to fully take into account the impact of all the drivers of changes identified in the scenarios. In order to simplify and thus manage the calculation of the values of the efficacy and safety of the new drug, managers' attention focused on a limited numbers of variables.

Finally, the provision of quantitative data made indeed the illustration of scenarios more vivid. However, we noticed that, when not directly involved in the scenario building process and the real option analysis, managers tended to find it more difficult to understand the origin and meaning of quantitative data.

\section{Conclusions}

This paper describes and develops an innovative methodological approach to scenario planning, which seamlessly embeds the pay-off method for real options valuation into the $2 \times 2$ scenario matrix. According to mainstream scholars and practitioners, we argue that the main contribution that scenarios are likely to bring to strategic decision makers is not to predict the future but to 
prepare them to handle future changes, by improving their learning and adaptive skills (Bradfield et al., 2005; de Geus, 1997; Grant, 2003). The methodological approach we illustrate in this paper aims exactly at fostering this process, by combining simplicity of understanding with easy of application and by integrating the qualitative insights of scenarios with the quantitative data of real options.

We describe our combined methodology in relation to the specific case of strategic investments in the biotechnology industry and the key variables of efficacy and safety: these variables were used as the two axes of the $2 \times 2$ scenario matrix. Anyway, our methodological framework might be easily extended to the cases of $R \& D$ investment decisions in other technology-driven industries (like the case of the information and communication business), by simply changing the axes of the $2 \times 2$ scenario matrix (e.g., the market share and the market size of a new product). Beyond R\&D investment projects, the methodological framework we introduce in this paper might be easily extended as well to the other traditional domains of application of real options, such as mergers and acquisitions, investments in new capacity, and international expansion (Krychowski and Quelin, 2010).

An important limitation of our integrated approach regards its use in strategic investment decisions for which the 'base case' scenario still requires the assessment of the relative probabilities of the 'intermediate scenarios' (i.e., scenarios '+;-' and '-;+' of Figure 3). In the absence of any framework to assess such relative probabilities, decision makers might assign the same likelihood (i.e., 50\%) to both intermediate scenarios. However, in this case the triangular approach might lead to a slightly inaccurate estimation of the uncertainty underlying capital investment decisions. The further development of the pay-off method from the triangular 
approach to the trapezoidal approach can be very useful for overcoming such limitation (Collan et al., 2012).

\section{Future research work}

Future research efforts should test the accuracy and reliability of our framework. We thus hope that scholars and practitioners might build upon our work in order to explore further and enhance the relationship between scenario planning, real options analysis and organizational learning (Vecchiato, 2015).

In this regard, is worth noting that the combined methodological approach we develop and present in this paper can be profitably applied in all the industries and domains where scenarios and real options have been already used so far. The pay-off method could be particularly relevant to mature global industries like the energy or the chemical business, where scenarios proved to be very helpful to cope with the growing uncertainty resulting from the huge number of drivers of change, the strict relationships and mutual influences among these drivers, and their low rate of evolution (Vecchiato, 2012). In such industries the pay-off method might be successfully combined with scenarios in order to progressively define and update the value of the strategic options resulting from the scenarios. Our methodology would be relevant also to technologybased industries, where R\&D investment processes are sequenced in different phases, similarly to the case of the pharmaceutical industry. At the end of each phase, decision makers can collect new data which enables them to reiterate and refine both the scenario process and the calculation of the value of real options.

On the other hand, the methodology we propose in this paper is likely to be less effective in highly dynamic industries, where the slow pace of scenario building does not match the frequent 
rise of new drivers of change in technologies and customer needs. That's the case, for instance, of the mobile communication industry (Vecchiato, 2012). In particular, Woiceshyn and Falkenberg (2008) argue that real options should not be used when firms have to cope with disruptive technologies or network externalities: in such cases, it is actually no possible to make reasonable assumptions about the value of the underlying assets (Coff and Laverty, 2001). Equally Adner and Levinthal (2004) argue that real options should not be used in the case of low degree of uncertainty and irreversibility of investments in new assets, as the NPV approach is more appropriate instead.

All these limitations to the use of real options apply to the pay-off method, hence to our methodological approach. However, we hope that this manuscript generates discussion among both academics and practitioners so that they can further develop and apply our framework in those domains where the qualitative limitations of scenarios or the quantitative limitations of real options previously prevented the full exploitation of each single technique. 


\section{References}

Adler, N., Shani, A.B., Styre, A. 2003. Collaborative Research in Organizations: Foundations for Learning, Change, and Theoretical Development. Sage Publications, Thousands Oaks, CA.

Adner, R., Levinthal, D. A. 2004. What is not a real option: Considering boundaries for the application of real options to business strategy. Academy of Management Review 29, 74 85.

Amer, M., Daim T.U., Jetter A. 2013. A review of scenario planning. Futures 46, 34-40.

Ansoff, H.I. 1991. Critique of Henry Mintzberg's The Design School: reconsidering the basic premises of strategic management”, Strategic Management Journal 12, 449 - 461.

Avadikyan, A, Llerena, P. 2010. A real options reasoning approach to hybrid vehicle investments. Technological Forecasting and Social Change 77, 649-661.

Baker. S.G., Lindeman, K.S. 2001. Rethinking historical control. Biostatistics 2,383-396

Barr, P.S., Stimpert, J.L., Huff, A.S. 1992. Cognitive change, strategic action, and organizational renewal. Strategic Strategic Management Journal 13, 15-36.

Battistella, C., De Toni, A. F. 2011. A methodology of technological foresight: A proposal and field study. Technological Forecasting and Social Change 78, 1029-1048.

Benaroch, M., Kauffman, R. 1999. A case for using real options pricing analysis to evaluate information technology project investments. Information Systems Research 10, 70-86.

Black, F., Scholes, M. 1973. The pricing of options and corporate liabilities, Journal of Political Economy 81, 637-659.

Boomsma, T.K., Meade, N., Fleten, S.E. 2012. Renewable energy investments under different support schemes: A real options approach. European Journal of Operations Research 220, $225-237$.

Borison, A. 2005. Real options analysis: Where are the emperor's clothes? Journal of Applied Corporate Finance 17, 17-31.

Bowman, E. H., Moskowitz, G. T. 2001. Real options analysis and strategic decision making. Organization Science 12, 772-777.

Bradfield, R. M., Wright, G., Burt, G., Cairns, G, van der Heijden, K. 2005. The origins and evolution of scenario techniques in long range planning. Futures 37, 795-812.

Chorn, L.G., Shokhor, S. 2006. Real options for risk management in petroleum development investments. Energy Economics 28, 489-505. 
Cirjevskis, A., Baduns, E. 2013. Transformation of scenario planning into a real options valuation in time of economic transition. Procedia Economics and Finance 5, 172 - 181.

Cobb, B. R., Charnes, J.M. 2004. Real options volatility estimation with correlated inputs. The Engineering Economist 49, 119-137.

Coff, R. W., Laverty, K. J. 2001. Real options on knowledge assets: Panacea or Pandora's box? Business Horizons 44, 73-79.

Collan, M., Fuller, R, Mezei, J. 2009. A fuzzy Pay-off method for Real Options valuation, Journal of Applied Mathematics and Decision Sciences 2009, 165-169.

Collan, M., Fuller, R, Mezei, J., 2012. Credibilistic approach to the fuzzy pay-off method for real option analysis. Journal of Applied Operational Research 4, 174-182.

Copeland, T. Tufano, P. 2004. A real-world way to manage real options. Harvard Business Review 82, 90-99.

Cornelius, P., Van de Putte, A., Romani, M. 2005. Three decades of scenario planning in Shell”, California Management Review 48, 92-109.

Cortazar, G., Schwartz, E. S., Salinas, M. 1998. Evaluating environmental investments: A real options approach.Management Science 44, 1059 -1070.

Courtney, H. 2001. 20/20 Foresight: Crafting Strategy in an Uncertain World, Harvard Business School Press, Boston, MA.

Damodaran A, 2005.The Promise and Peril of Real Options. NYU Working Paper (S-DRP-0502).

Damodaran A, 2006. Damodaran on valuation: security analysis for investments and corporate finance $\left(2^{\text {nd }}\right.$ ed. $)$. Wiley, Hoboken, New Jersey

Davis G. 2002. Scenarios as a tool for the 21st century. Paper presented at Probing the Future Conference, Glasgow, UK.

Davis P., Pyper N. 2015. Enacting a new approach to scenario analysis: the potential of a pragmatist account, Foresight 17, 427- 443.

de Geus, A. 1997. The Living Company. Harvard Business School Press, Boston, MA.

De Meyer, A., Loch, C. H., Pich, M.T. 2002. Managing project uncertainty: from variation to chaos", Sloan Management Review 43, 60-67.

DiMasi J A et al. 2013. Clinical approval success rates for investigational cancer drugs. Clinical Pharmacology \& Therapeutics 94, 329-35

Dixit, A. K., Pindyck, R. S. 1994. Investment under uncertainty. Princeton University Press: Princeton, NJ. 
Dortland, M v. R., Dewulf, G., Voordijk H. 2012. Towards a decision support tool for real estate management in the health sector using real options and scenario planning. Journal of Corporate Real estate 14, 140 - 156.

Dortland, M.v. R., Dewulf, G., Voordijk, H. 2014, Making sense of future uncertainties using real options and scenario planning. Futures 55, 15-31.

Doz, Y., Kosonen, M. 2008. Fast Strategy: How Strategic Agility Will Help You Stay Ahead of the Game. Wharton School Publishing, Philadelphia, PA.

Dreyling M, Ghielmini M, Marcus R, Salles G and Vitolo U (2011) Newly diagnosed and relapsed follicular lymphoma: ESMO Clinical Practice Guidelines for diagnosis, treatment and follow-up. Annals of Oncology 22, 59 - 63.

Duncan, R.B. 1972. Characteristics of organizational environments and perceived Environmental uncertainty. Administrative Science Quarterly 17, 313-327.

Eisenhardt, K. M., Furr, N. R., Bingham, C. B. 2010. Microfoundations of performance: Balancing efficiency and flexibility in dynamic environments. Organization Science 21, 1263-1273.

Favato, G, Cottingham, J.A., Isachenkova N. 2015. Blending Scenarios into Real Options: Relevance of the Pay-off Method to Management Investment Decisions. Journal of Finance and Accounting 3,12-17

Forstpointner R, Dreyling M, Repp R, Hermann S, Hänel A, Metzner B, Pott C, Hartmann F, Rothmann F, Rohrberg R, Böck HP, Wandt H, Unterhalt M, Hiddemann W. 2004. The addition of rituximab to a combination of fludarabine, cyclophosphamide, mitoxantrone (FCM) significantly increases the response rate and prolongs survival as compared with FCM alone in patients with relapsed and refractory follicular and mantle cell lymphomas: results of a prospective randomized study of the German Low-Grade Lymphoma Study Group. Blood 104, 3064 - 3071

Franco, L. A, Meadows, M., Armstrong, S. J. 2013. Exploring individual differences in scenario planning workshops: a cognitive style framework. Technological Forecasting and Social Change 80, 723-734.

Galbraith, C. S., Merrill, G. B. 1996. The politics of forecasting: Managing the truth. California Management Review 38, 29-43.

Grant, R. M. 2003. Strategic Planning in a Turbulent Environment: Evidence from the oil majors. Strategic Management Journal 24, 491-517.

Greenwood, D.J., Levin, M. 1998. Introduction to action research: social research for social change. Sage Publications, Thousand Oaks.

Hay, M., Thomas, D.W., Craighead, L., Ecomides C., Rosenthal, J. 2014. Clinical development success rates for investigational drugs. Nature Biotechnology 32, 40-51. 
Ingvar, D.H. 1985. Memory of the future: an essay on the temporal organization of conscious awareness. Human Neurobiology 4, 127-136.

Kaplan, R., Norton D. 1993. Putting the Balanced Scorecard to Work. Harvard Business Review 71, 134-147.

Kellog, D., Charnes, J.M. 2002. Real-options valuation for a biotechnology company. Financial Analysts Journal 56, 76-84.

Knight F. H. 1921. Risk, Uncertainty, and Profit, Hart, Schaffner \& Marx, New York.

Krychowski C., Quelin, B. 2010. Real Options and Strategic Investment Decisions: Can They Be of Use to Scholars? Academy of Management Perspectives 24, 65-78

Lander, D. M., Pinches, G. E. 1998. Challenges to the practical implementation of modeling and valuing real options. Quarterly Review of Economics \& Finance 38, 537-567.

Maloney Dg et al. (1997) IDEC-C2B8 (Rituximab) anti-CD20 monoclonal antibody therapy in patients with relapsed low-grade non-Hodgkin's lymphoma. Blood 90, 2188-2195

McGrath, R. G., Ferrier, W. J., Mendelow, A. L. 2004. Real options as engines of choice and heterogeneity. Academy of Management Review 29, 86-101.

McGrath, R. G., Nerkar, A. 2004. Real options reasoning and a new look at the R\&D investment strategies of pharmaceutical firms. Strategic Management Journal 25, 1-22.

McGrath, R. G., Nerkar, A. 2004. Real options reasoning and a new look at the R\&D investment strategies of pharmaceutical firms. Strategic Management Journal 25, 1- 22.

Mills R. W., Weinstein B., Favato, G. 2006. Using scenario thinking to make real options relevant to managers: a case illustration. Journal of General Management 31, $49-74$.

Miller, K. D., Waller, H. G. 2003. Scenarios, real options and integrated risk management. Long RangePlanning 36, 93-107.

Mintzberg, H. 1990. The design school: reconsidering the basic premises of strategic management. Strategic Management Journal11, 171-195.

Narang, A. S., Desay, D.S. 2009. Unique Aspects of Pharmaceutical Development Anticancer Drug Development, 49-92

O'Brien, F.A., Meadows, M. 2013. Scenario orientation and use to support strategy development. Technological Forecasting and Social Change 80, 643-656.

P. Malaska. 1985. Multiple Scenario Approach and Strategic Behaviour in European Companies. Strategic Management Journal 6, 339 - 366.

Paddock, J.L., Siegel, D.R, Smith, J.L. 1988. Option valuation of claims on real assets: the case of offshore petroleum leases. The Quarterly Journal of Economics 103, 479-508. 
Paul, S.M, Mytelka D.S., Dunwiddie C.T., Persinger C.C., MunosB.H., LindborgS.R., Schacht A.L., 2010. How to improve R\&D productivity: the pharmaceutical industry's grand challenge Nature Reviews Drug Discovery 9, 203-214.

Pennings, E., Lint, O. 2000. Market entry, phased rollout or abandonment? A real option approach. European Journal of Operational Research 124, 125-138.

Porter, A.L., Ashton, B., Clar, G., Coates, J.F., Cuhls, K., Cunningham, S.W., Ducatel, K., Van der Duin, P., Georghiou, L., Gordon, T., Linstone, H., Marchau, V., Massari, G., Miles, I., Mogee, M., Salo, A., Scapolo, F., Smits, R., Thissen, W. 2004. Technology futures analysis: toward integration of the field and new methods. Technological Forecasting and Social Change 71, 287-303.

Porter, M.E. 1980. Competitive Strategy, The Free Press, New York.

R. Linneman, H. Klein. 1983.The Use of Multiple Scenarios by US Industrial Companies: A Comparison Study 1977-1981. Long Range Planning 16, 94 -101.

Ram, C., Montibeller, G. 2013. Exploring the impact of evaluating strategic options in a scenario-based multi-criteria framework, Technological Forecasting and Social Change 80, $657-672$.

Rocha, K., Salles, L., Garcia, F.A.A. 2007. Real estate and real options: A case study. Emerging Markets Review 8, 67-79.

Rohrbeck, R., Schwarz, J. O. 2013.The value contribution of strategic foresight: insights from an empirical study of large European companies, Technological Forecasting and Social Change 80, 1593-1606.

Schoemaker, P. J. H. 1993. Multiple scenario development: its conceptual and behavioural foundation, Strategic Management Journal 14, 193-213.

Schwartz, P. 1991. The art of the long view: Planning for the future in an uncertain world. Doubleday Currency, New York.

Smit, H.T.J., Trigeorgis, L. 2006. Real options and games: Competition, alliances and other applications of valuation and strategy. Review of Financial Economics 15, 95-112.

Smith, J.E., McCardle, K.F. 1999. Options in the real world: Lessons learned in evaluating oil and gas investments. Operations Research 47, 1-15.

Tapinos, E., Dyson, R. G., Meadows, M. 2005. The impact of performance measurement in strategic planning. International Journal of Productivity and Performance 54, 370-384.

Taudes, A., Feurstein, M., Mild, A. 2000. Options analysis of software platform decisions: A case study. MIS Quarterly 24, 227-243. 
Teece D.J. 2007. Explicating dynamic capabilities: the nature and microfoundations of (sustainable) enterprise performance, Strategic Management Journal 28, 1319-1350.

Tong, T. W., \& Reuer, J. J. 2007. Real options in strategic management. In J. J. Reuer \& T. W. Tong (Eds.), Advances in Strategic Management (Vol. 24, pp. 3-28). Emerald Group Publishing Ltd, Greenwich.

Triantis, A. J. 2005. Realizing the potential of real options: Does theory meet practice? Journal of Applied Corporate Finance 17, 8-16.

Trigeorgis, L. 1996. Real options. Managerial flexibility and strategy in resource allocation. MIT Press, Cambridge, MA.

Tripsas, M., Gavetti, G. 2000. Capabilities, cognition, and inertia: evidence from digital imaging. Strategic Management Journal 21, 1147-1162.

Ulrich, C. 2013. Valuation of IT investments using real options theory. Business \& Information Systems Engineering 5, 331 - 341.

van der Heijden, K. 1996. Scenarios: The art of strategic conversation. Wiley, New York.

van der Heijden, K., Bradfield, R., Burt, G., Crains, G., Wright, G. 2002. The Sixth Sense: Accelerating Organisational Learning with Scenarios, Wiley, Chichester.

Vecchiato, R. 2012. Environmental uncertainty, foresight and strategic decision making: an integrated study, Technological Forecasting and Social Change 79, 436-447.

Vecchiato, R. 2015. Creating value through foresight: First mover advantages and strategic agility, Technological Forecasting and Social Change 101, 25 - 36.

Vecchiato, R., Roveda, C. 2010. Foresight in Corporate Organizations, Technology Analysis \& Strategic Management 22, 99 - 112.

Vecchiato, R., Roveda, C. 2010. Strategic foresight in corporate organizations: assessing the effect and response uncertainty of technology and social drivers of change. Technological Forecasting and Social Change 77, 1527-1539.

Wack, P. 1985. Scenarios: Uncharted waters ahead. Harvard Business Review, 6373 -89.

Woiceshyn, J., Falkenberg, L. 2008. Value creation in knowledge-based firms: Aligning problems and resources. Academy of Management Perspectives 22, 85 -99.

Wright, G., Bradfield R, Cairns G. 2013. Does the intuitive logics method - and its recent enhancements - produce "effective" scenarios? Technological Forecasting and Social Change 80, 631- 642 . 